Anuario Latinoamericano Ciencias Políticas y Relaciones Internacionales vol. 7, 2019

pp. $17-74$

\section{La dimensión político-institucional de los procesos de integración de América Latina (2000-2016)}

DOI: 10.17951/al.2019.7.17-74

\section{The Political-Institutional Dimension of the Integration Processes of Latin America (2006-2016)}

\author{
Alberto Rocha Valencia * \\ DIVISIÓN DE ESTUDIOS DE ESTADO Y SOCIEDAD \\ DEPARTAMENTO DE ESTUDIOS IBÉRICOS Y LATINOAMERICANOS \\ UNIVERSIDAD DE GUADALAJARA \\ MÉXICO \\ $\triangle$ albertorochav@yahoo.com.mx \\ https://orcid.org/0000-0002-5570-9872
}

\title{
RESUMEN
}

Este trabajo aborda el análisis de la dimensión político-institucional del tercer periodo del proceso de integración regional (2000-2015/16) de ALC, que se distinguió por haber propiciado un impulso sustantivo de éste y se caracterizó por ser progresista y semi-abierto. No solamente los procesos subregionales avanzaron (MERCOCUR, UNASUR, PIM, SICA, CARICOM, AP, ALBA), sino que con la creación de la CELAC (foro político y diplomático regional) se logró constituir un bosquejo de gobernabilidad-gobernanza regional que generó unidad y autonomía.

PALABRAS CLAVE: Latinoamérica, integración, gobernabilidad, gobernanza, procesos, instituciones, tratados, gobiernos, progresismo, neoliberalismo, multilateralismo, bilateralismo, autonomía.

\section{ABSTRACT}

This article addresses the analysis of the political-institutional dimension of the third period of the regional integration process (2000-2015/16) of LAC, which was dis-

* Doctor por la Universidad de Paris VIII, 1982, Francia. Profesor Investigador Titular C y Jefe del Departamento de Estudios Ibéricos y Latinoamericano-DEILA; Profesor de la Licenciatura en Relaciones Internacionales del Departamento de Estudios Internacionales; Profesor de la Maestría en Relaciones Económicas Internacionales y Cooperación (Énfasis en ALC y UE) del Centro Universitario en Ciencias Económicas y Administrativas: Profesor de la Maestría y Doctorado en Ciencias Políticas del Departamento de Estudios Políticos del Centro Universitario de Ciencias Sociales y Humanidades de la Universidad de Guadalajara. Miembro del Sistema Nacional de Investigadores-SNI, CONACYT, México. 
Dossier América Latina: continuidad y cambio en el escenario regional tinguished by having fostered a substantive impetus of this process and had a progressive and semi-open character. Not only did the subregional processes advance (MERCOSUR, UNASUR, PIM, SICA, CARICOM, AP, ALBA), but with the creation of CELAC (a regional political and diplomatic forum) it was possible to establish a regional governability-governance outline that generated unity and autonomy.

KEYWORDS: Latin America, integration, governability, governance, processes, institutions, agreements, governments, progressivism, neoliberalism, multilateralism, bilateralism, autonomy.

\section{INTRODUCCIÓN}

En este trabajo se abordan las cuestiones de la gobernabilidad y gobernanza en los planos regional y subregional del proceso de integración de la región, con la finalidad de explorar la relación entre los procesos de gobernabilidad y gobernanza de los esquemas político-institucionales de los procesos de integración subregionales y el esquema de gobernabilidad y gobernanza del proceso de integración regional. Lo anterior solamente será posible si antes se realiza un recorrido analítico por cada una de las dimensiones político-institucionales de los procesos de integración regional y subregional existentes ${ }^{1}$, para clasificarlas en función de sus organigramas y luego en relación con los cuadros de análisis político-institucional. Antes de avanzar, dejamos constancia que en este escrito no se incursionará en las dinámicas desplegadas por cada uno de los esquemas político-institucionales de los procesos de integración regional y subregional.

Como resultado de este recorrido analítico hemos clasificado a las dimensiones político-institucionales de los procesos de integración en cuatro categorías:

- Forma político-institucional simple de gobernanza sencilla

- Forma político-institucional relativamente avanzada

- Forma político-institucional avanzada y dinámica

- Forma político-institucional amplia y compleja

A cada una de estas formas le corresponden diferentes prácticas de gobernabilidad y gobernanza: gobernanza llana, gobernanza intensa con rasgos de una gobernabilidad germinal, gobernanza fuerte acompañada de una gobernabilidad creciente y gobernabilidad establecida.

Hasta antes de los inicios de los años dos mil, los esquemas político-institucionales de los procesos de integración subregionales y regionales se presentaban muy de manera dispersa y desvinculados. En el periodo de 2000-2015/16 se ensaya un proceso de gobernabilidad autónoma regional a partir de la crea-

1 Sobre el tema de las instituciones de los procesos de integración regional y subregional se pueden consultar los libros de Noemí Beatriz Mellado (ed.) (2009, 2010 y 2012), los libros Alberto Rocha V. et al. $(1997,2002,2003,2006,2007,2008,2016)$ y los trabajos de este mismo autor (2001, 2007, 2013, 2014 y 2015). En estos trabajos se pueden consultar los análisis realizados sobre las dinámicas de los esquemas político-institucionales de los niveles regional y subregional. 
ción y puesta en funcionamiento de la Comunidad de Estados Latinoamericanos y Caribeños - CELAC. Este ensayo de gobernabilidad autónoma regional buscaba sincronizarse con las experiencias de gobernanza y gobernabilidad subregionales existentes. Ahora bien, en este periodo, entre la gobernabilidad del plano regional y las gobernanzas y gobernabilidades del plano subregional no hay buena correspondencia, debido a las inercias existentes y a las situaciones de intergubernamentabilidad prevalecientes en ambos planos, pero esto no impidió que se formaran consensos y se impulsaran una dinámica interna regional y una dinámica externa regional; ambas dinámicas generadoras de cohesión, unidad y autonomía de la región. Existió pues una tensión entre la "homogeneidad" del esquema político-institucional de la CELAC (de una institución joven) y a la "heterogeneidad" de los esquemas político-institucionales (una diversidad de instituciones) de los procesos de integración subregionales.

Para lograr una mejor contextualización de este trabajo presentamos los periodos de desenvolvimiento de la integración regional, con la finalidad de colocar el énfasis en el tercero de ellos y dejar sentado que se ha iniciado uno nuevo: a) Primer periodo 1960-1980: el regionalismo cerrado y su lógica de desarrollo hacia adentro (de cuño estructuralista) sustentado en el modelo de industrialización por sustitución de importaciones - ISI.

b) Segundo periodo 1980-2000: el regionalismo abierto y su lógica de desarrollo hacia afuera (de matriz neoliberal) que reposaba sobre la acción externa de los capitales (de afuera hacia adentro) y la dinámica económica volcada hacia las exportaciones.

Hasta aquí tenemos los siguientes procesos de integración: Asociación Latinoamericana de Integración (ALADI), Grupo de Río, Parlamento Latinoamericano (PARLATINO), Sistema Económico Latinoamericano (SELA), Comunidad Andina (CAN), Mercado Común del Sur (MERCOSUR), Grupo de los (G-3), Sistema de Integración Centroamericano (SICA), Caribbean Community and Common Market (CARICOM), Asociación de Estados del Caribe (AEC) y un conjunto de acuerdos bilaterales. Sobre estos dos primeros periodos consultar (Rosenthal 1993, Salazar 1993, Vieira 2006, Sanahuja 2006, Gudynas 2006).

c) Tercer periodo 2000-2015/16: el regionalismo alternativo y semiabierto (cercano del neoestructuralismo y del nuevo desarrollismo), impulsado por los gobiernos progresistas.

En este periodo, los primeros cambios se producen en el nivel subregional cuando se inicia la convergencia integradora de México con el SICA. Entonces, aparece el espacio de integración mesoamericano, primero llamado Plan Puebla Panamá-PPP y, más adelante, Proyecto Mesoamericano-PM. De este modo, toma forma una suerte de mesoregión de integración; por supuesto muy influida por el rol de México como potencia regional. Luego toma forma el Área de Libre Comercio de Sudamérica, con base en la convergencia integradora entre el MERCOSUR, la CAN y Chile. Este proceso dará lugar después a la Comunidad Sudame-

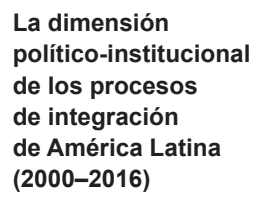

Alberto Rocha Valencia 
Dossier América Latina: continuidad y cambio en el escenario regional ricana de Naciones y, finalmente, a la Unión de Naciones SudamericanasUNASUR (ahora se añaden Surinam y Guyana). Entonces toma forma la segunda mesoregión, liderada por la otra potencia regional, Brasil. En seguida se funda la Alternativa Bolivariana de las Américas-ALBA y Venezuela decide salir de la CAN para incorporarse al MERCOSUR. Finalmente, se funda la CELAC, como foro político y diplomático regional (en sustitución del Grupo de Río) y casi al mismo tiempo se crea la Alianza del Pacífico-AP en el nivel subregional. Esta tercera etapa se habría cerrado con el declive relativo de los gobiernos progresistas y la crisis de los modelos económicos neo-extractivistas, debido a la caída de los precios de las materias primas (petróleo, gas y minerales diversos). Este periodo puede llamarse "alternativo" puesto que los gobiernos progresistas se propusieron un modelo económico desarrollista, semiestatista, de bienestar, democrático y con orientaciones geoeconómicas y geopolíticas sur-sur (China, Rusia e India). Brasil, como potencia regional, miembro del BRICS, fue el líder en todo este periodo. Una cuestión fue fundamental en este periodo, la autonomía de los países y la autonomía de la región. Estas propuestas se encuentran expuestas en la obra Dimensiones, estrategias y alternativas de la integración autónoma para América Latina y el Caribe. Desafíos para el caso mexicano (Preciado Coronado 2018) y en Sentido de la investigación sobre la integración autónoma de la integración de América Latina y el Caribe. Fundamentos teóricos y metodológicos (Preciado Coronado 2018).

Recordamos que varios autores han llamado a este periodo como el de "integración posliberal", "posneoliberal” y "poshegemónica”. Nombramos el caso de José Antonio Sanahuja quien enumera algunas de sus características más importantes: a) la primacía de la agenda política y una menor atención a la agenda económica y comercial; b) el retorno de la "agenda de desarrollo", en el marco de las agendas económicas del "post-Consenso de Washington"; c) un mayor papel de los actores estatales frente al protagonismo de los actores privados y las fuerzas del mercado; d) un énfasis mayor en la agenda "positiva" de la integración, centrada en la creación de instituciones y políticas comunes y en una cooperación más intensa en ámbitos no comerciales; e) mayor preocupación por las dimensiones sociales y las asimetrías en cuanto a niveles de desarrollo; f) la búsqueda de fórmulas para promover una mayor participación y la legitimación social de los procesos de integración (Sanahuja 2009).

d) Cuarto periodo, desde 2016 hacia adelante: el regreso del "regionalismo abierto" (muy controvertido, por cierto, por la crisis general del neoliberalismo y del consenso de Washington), la vuelta relativa de nuevos-viejos gobiernos conservadores neoliberales y el proceso de rearticulación de la región con los Estados Unidos del conservador proteccionista D. Trump. Según autores como Jorge Garzón y Detlef Nolte, habríamos ingresado a una nueva etapa que ellos definen como la del "regionalismo cruzado", propio de un contexto de crisis del neoliberalismo, de transición hacia un 
mundo multipolar y de prácticas acentuadas de relaciones bilaterales entre los procesos de integración regional (Garzón 2015; Garzón, Nolte 2016).

En esta investigación se abordarán los puntos siguientes: primero, el tema de la gobernabilidad y gobernanza en un sistema político nacional, en el sistema político internacional y en el sistema-mundo emergente, de manera muy resumida.

\section{Gobernabilidad y gobernanza}

\section{El nivel espacial nacional del sistema-mundo moderno}

En un sistema político nacional: Gobernabilidad = dirección política + gobernanza. Gobernabilidad es la "capacidad de gobernar" (frase tomada de Yehezkel Dror 1994). Dirección política es la definición de una estrategia gubernamental resultado de la toma de decisiones por la élite política gubernamental en función de los apoyos que recibirá de los actores de la sociedad civil; este es el eje de la legitimidad del gobierno. Gobernanza es la gestión de los
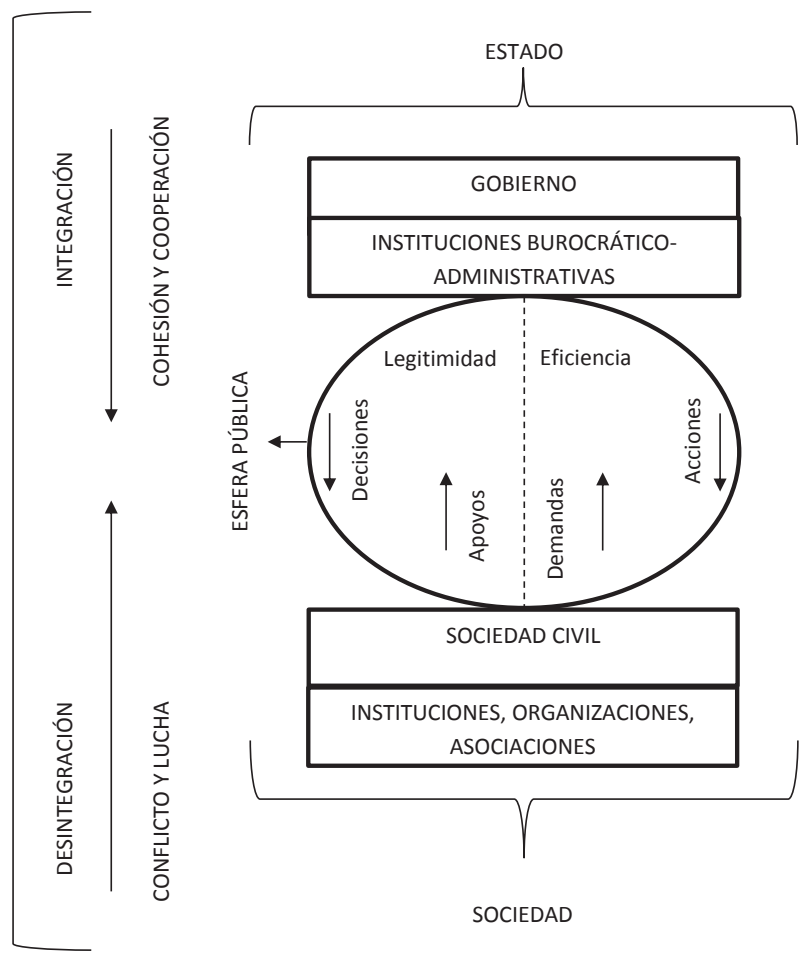

La dimensión político-institucional de los procesos de integración de América Latina (2000-2016)

Alberto Rocha Valencia
Gráfico 1.

Esquema del Sistema Político Nacional (SPN)

Fuente: elaboración propia. 
Dossier América Latina: continuidad y cambio en el escenario regional asuntos públicos resultante de las acciones (políticas públicas) emprendidas por la élite política gubernamental en relación con las demandas procesadas por los actores de la sociedad civil; este es el eje de la eficiencia del gobierno (Rocha Valencia 2003). De esta manera, gobernabilidad implica legitimidad y eficiencia. Un buen gobierno es el que combina adecuadamente legitimidad y eficiencia, es decir, el que dispone de capacidad para gobernar. En síntesis, la gobernabilidad es la variable dependiente y la dirección política y la gobernanza son variables independientes (Prats 2000; Camou 2008; Briceño 2018).

\section{El nivel internacional}

En el sistema político internacional de la Guerra Fría y Posguerra Fría se presentaron tres situaciones:

a) Durante la Guerra Fría (la bipolaridad) los dos hegemones (por separado) se encargaron de establecer la dirección política en Occidente y en Oriente. En esta medida, la Organización de las Naciones Unidas (ONU) por medio del Consejo Económico y Social (ECOSOC) y las instituciones internacionales especializadas de cooperación solamente lograron impulsar una gobernanza internacional (por medio de la cooperación internacional), pues el Consejo de Seguridad (CS) estaba paralizado por el veto de las dos superpotencias.

b) En Posguerra Fría I (la unipolaridad) 1990-2000) la dirección política la imparte el el Grupo de los Siete (G-7). Esto quiere decir que la ONU solamente impulsa una gobernanza internacional (haciendo uso de la cooperación internacional) y esto porque el CS sigue paralizado por el veto.

c) En Posguerra Fría II (la unipolaridad desafiada) (2000-2016) la elaboración e impartición de la dirección política se complica, pues ahora el G-7 y el Foro Brasil, Rusia, India, China y Sudáfrica (BRICS) compiten abiertamente por impartir dirección política. En consecuencia, la ONU sigue impulsando una gobernanza internacional, debido a que el CS sigue siendo un campo de disputa de los grandes poderes estatales.

En síntesis, la ONU en los tres momentos no pudo producir dirección política, la dirección política provenía o de los hegemones, o del G-7 y de los BRICS. Pero lo importantes es que siempre se logró generar una gobernabilidad sui generis en cada momento en el sistema político internacional; de allí que cuando nos referimos a la ONU, al ECOSOC y el sistema de Instituciones Internacionales hablamos solamente de gobernanza internacional (Rocha Valencia 2003).

\section{El sistema-mundo emergente}

El mundo emergente es multinivel: global, regional, posnacional y local; eso quiere decir que en cada uno de los cuatro niveles se plantean las cuestiones de 
la gobernabilidad-gobernanza, aunque de diferentes maneras y con diferentes alcances. Veamos (Rocha Valencia 2003):

a) En el nivel global, es una apuesta futura la gobernabilidad y la gobernanza; existen problemas globales, empresas transnacionales y actores sociales transnacionales, pero no hay una sola institución que se la pueda llamar global.

b) En el nivel regional, todavía es una promesa la concreción de la gobernabilidad y la gobernanza, esto debido al proceso heterogéneo de conformación de los sistemas político-institucionales regionales.

c) En el nivel posnacional, los procesos de gobernabilidad-gobernanza se están redefiniendo en relación con los cambios de los sistemas políticos nacionales debido a los procesos de integración regional y a los procesos de globalización.

d) En el nivel local, se siguen consolidando los sistemas políticos locales subnacionales y de igual manera los procesos de gobernabilidad-gobernanza.

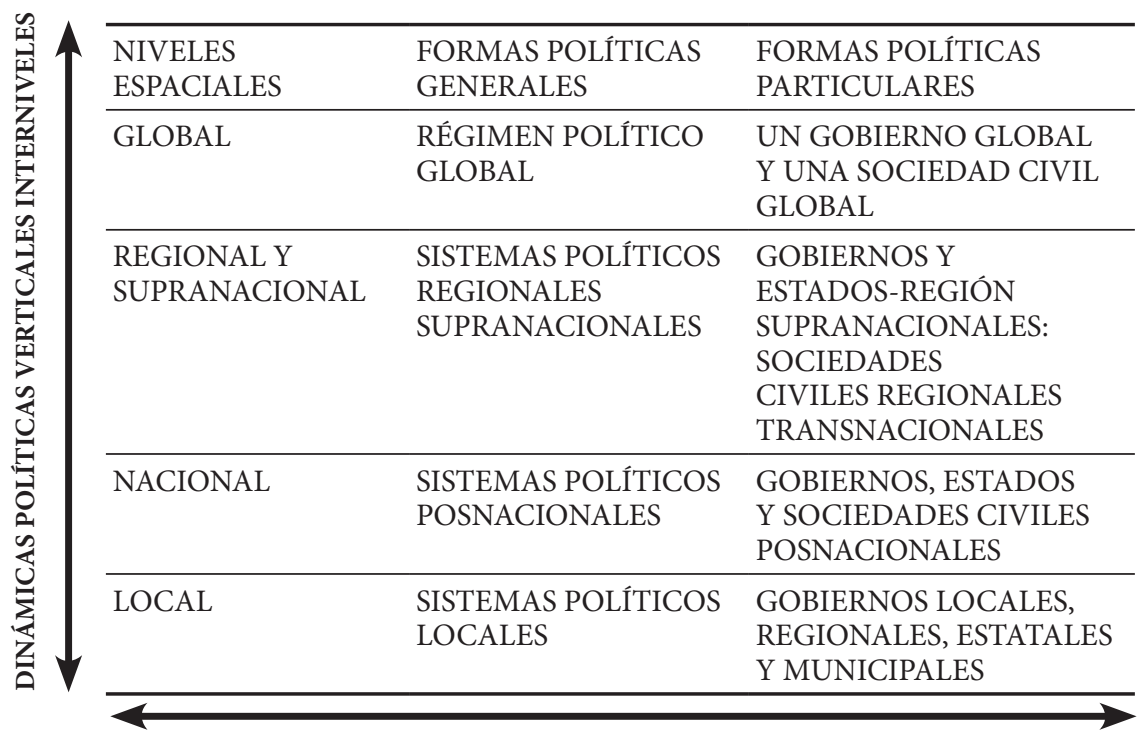

DINÁMICAS POLÍTICAS HORIZONTALES INTRANIVELES
La dimensión político-institucional de los procesos de integración de América Latina (2000-2016)

Alberto Rocha Valencia

\section{Cuadro 1.}

El Sistema Político Mundial Virtual del Siglo XXI

Fuente: Configuración política de un mundo nuevo (Rocha Valencia 2003). 


\section{Dossier Clasificación de las dimensiones político-institucionales América Latina: \\ continuidad y cambio en el escenario regional (dpi) de los procesos de integración regional y subregional de acuerdo con sus organigramas}

Con base en los organigramas de las DPI hacemos una clasificación en cuatro grupos $^{2}$ :

\section{Esquemas simples: TLC México-Colombia y TLC México-Chile}

Se trata de instituciones sencillas económico-comerciales o similares, donde los actores principales son las tecnocracias nacionales. En estos esquemas no hay lugar alguno para la participación de la sociedad civil. En este grupo se pueden anotar todos los Tratados de Libre Comercio (TLC) bilaterales y algunos Acuerdos de Complementación Económica (ACE).

Gráfico 2.

Tratado de Libre Comercio

México-Colombia

Gráfico 3.

Tratado de Libre Comercio México-Chile

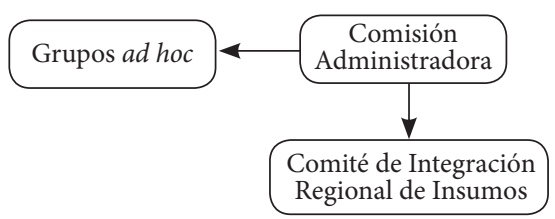

Fuente: elaboración propia.

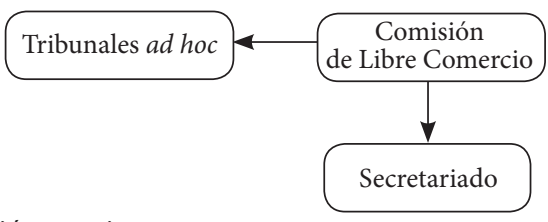

Fuente: elaboración propia.

Esquemas relativamente avanzados: ALBA, AEC y PIM

Estos esquemas están constituidos por instituciones políticas de decisión-ejecución débiles. Predominan las instituciones económico-comerciales y algunas otras. Las instituciones administrativas tienen menor presencia. Las instituciones sociales no están presentes y sólo son germinales en el ALBA. Los actores principales siguen siendo las tecnocracias, pero ya se manifiestan las élites políticas gubernamentales nacionales, aunque en el ALBA estas élites están más presentes. En este grupo anotamos a tres procesos de cooperación con relativos avances.

\footnotetext{
2 Consultar Dimensiones, estrategias y alternativas de la integración autónoma para América Latina y el Caribe, Tomo II Preciado Coronado 2018.
} 


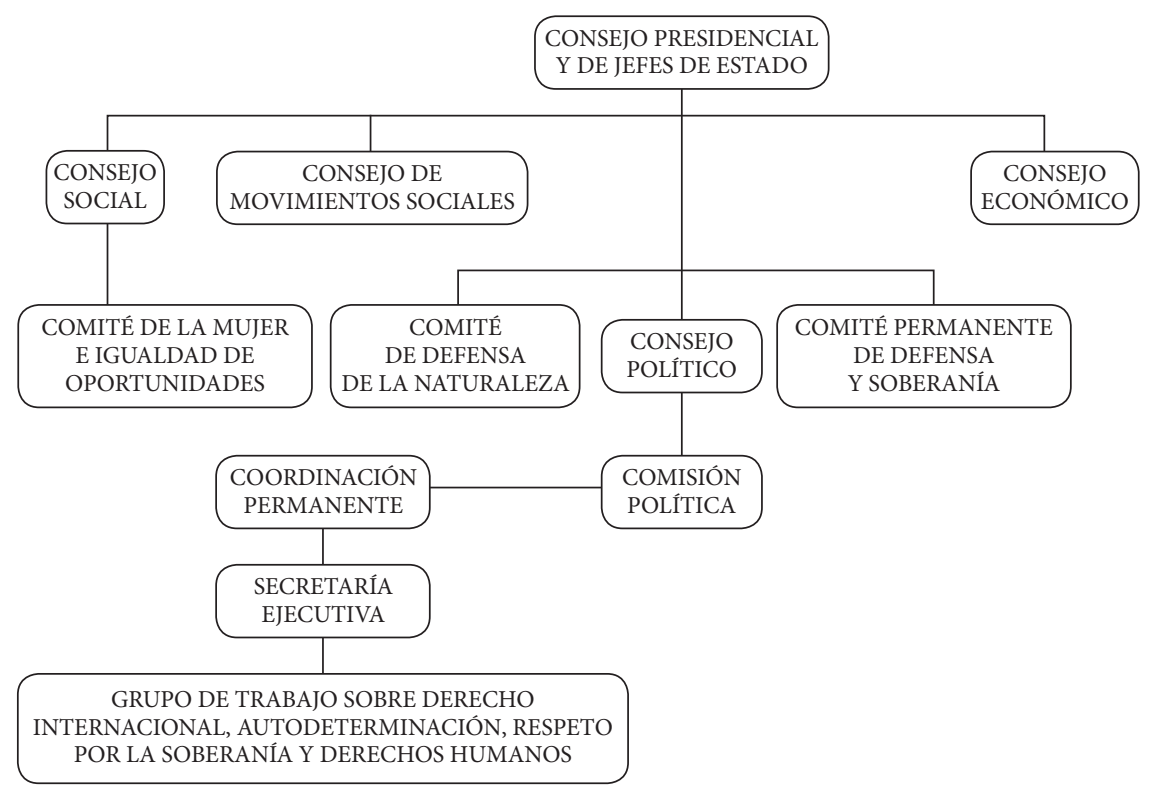

Fuente: elaboración propia.

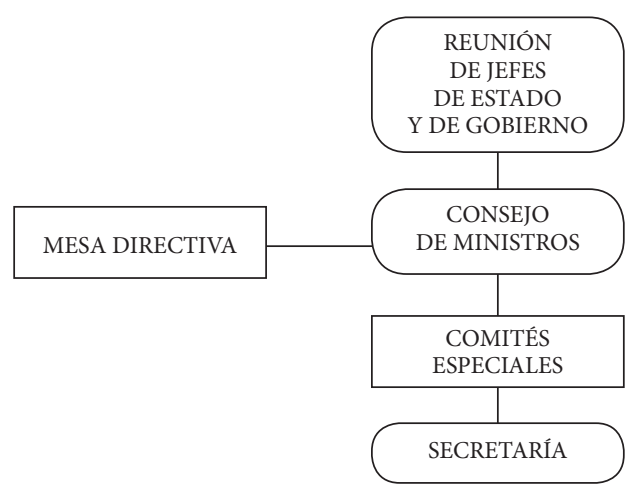

\section{COMITÉS ESPECIALES}

- Comité Especial de Desarrollo del Comercio y las Relaciones Económicas Externas

- Comité Especial de Transporte

- Comité Especial de Turismo Sustentable

- Zona de Turismo Sustentable del Gran Caribe

- Comité Especial de Reducción del Riesgo de Desastres

- Comité Especial de Presupuesto y Administración

Planes de acción bianuales:

2014-2016 - Declaración de Mérida

2016-2018 - Declaración de la Habana

Fuente: elaboración propia.
La dimensión

político-institucional

de los procesos

de integración

de América Latina

(2000-2016)

Alberto Rocha Valencia

\section{Gráfico 4.}

Alianza Bolivariana para los Pueblos de Nuestra América Latina (ALBA-TCP)

\section{Gráfico 5.}

Asociación de Estados del Caribe (AEC) 


\section{Dossier \\ América Latina: \\ continuidad y cambio \\ en el escenario regional}

Proyecto de Integración

y Desarrollo

Mesoamericano (PIM)

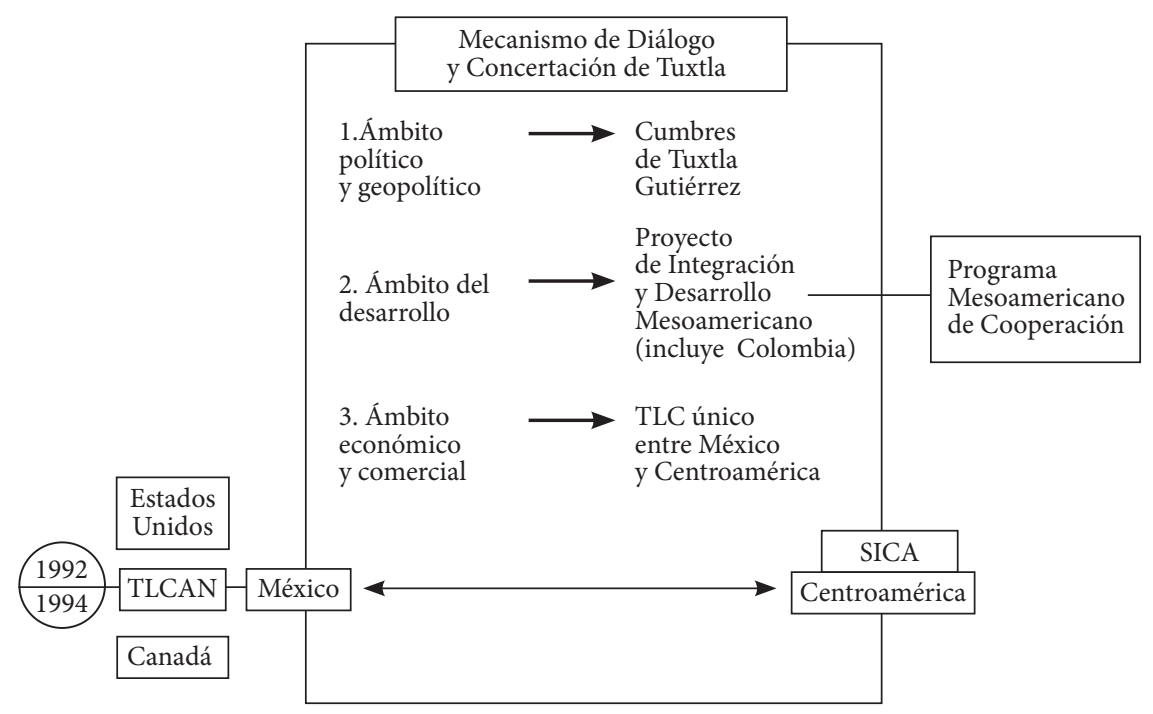

Fuente: elaboración propia.

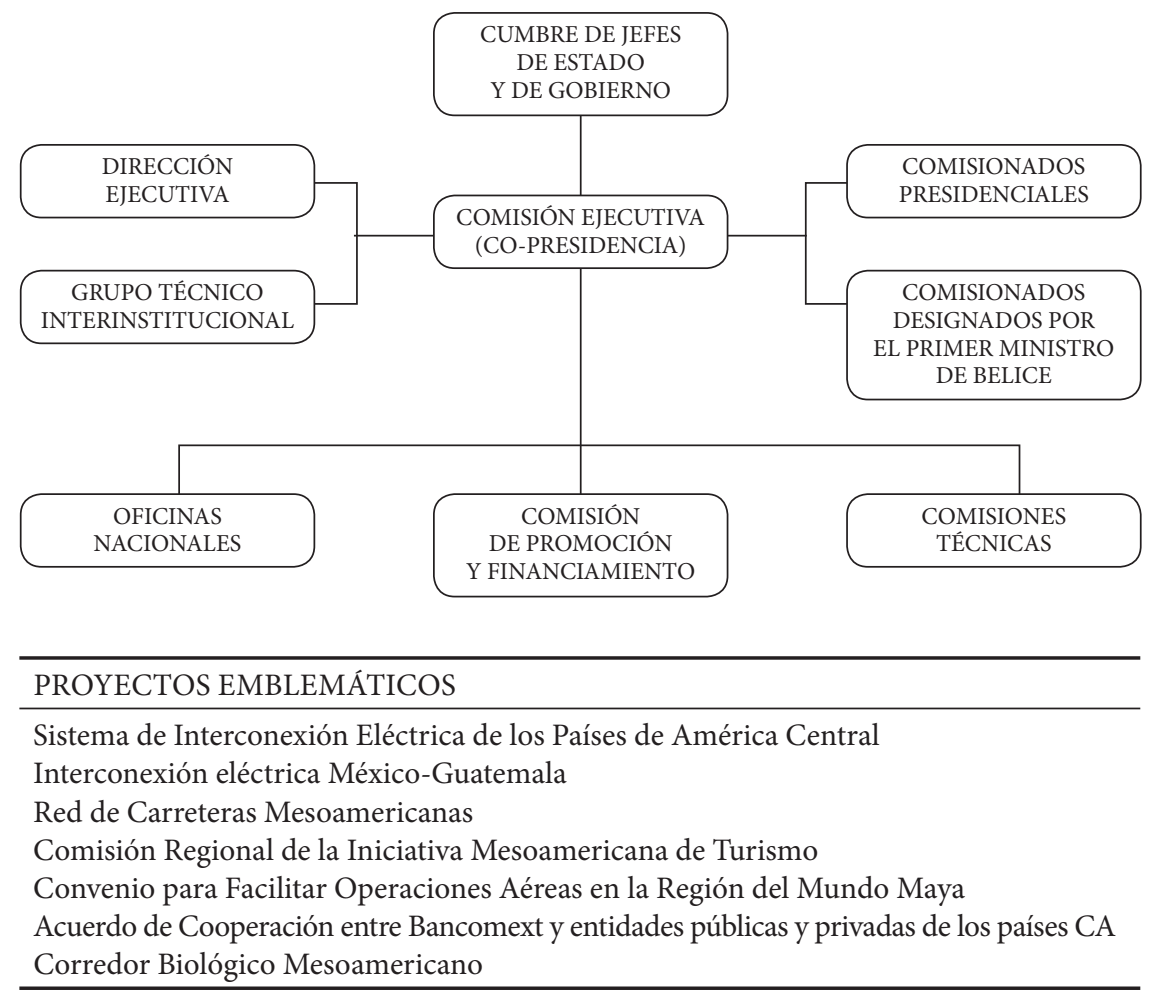

Fuente: elaboración propia.

Gráfico 7. Convenio para Facilitar Operaciones Aéreas en la Región del Mundo Maya

Proyecto Acuerdo de Cooperación entre Bancomext y entidades públicas y privadas de los países CA

Mesoamérica (PM) 
Esquemas avanzados y dinámicos: CELAC, UNASUR y AP

En estos esquemas las instituciones políticas de decisión-ejecución están medianamente constituidas, pero ya ocupan el centro de los organigramas. En la AP predominan las instituciones comerciales y otras. Las instituciones técnicas y administrativas tienen mayor relevancia. Las instituciones sociales están presentes inicialmente de una u otra manera. Las élites políticas gubernamentales han ocupado lugares importantes y centrales, pero las tecnocracias siguen estableciéndose con más fuerza. En este grupo anotamos tres procesos de integración destacados, donde la AP y la UNASUR son mucho más que sencillos TLC.

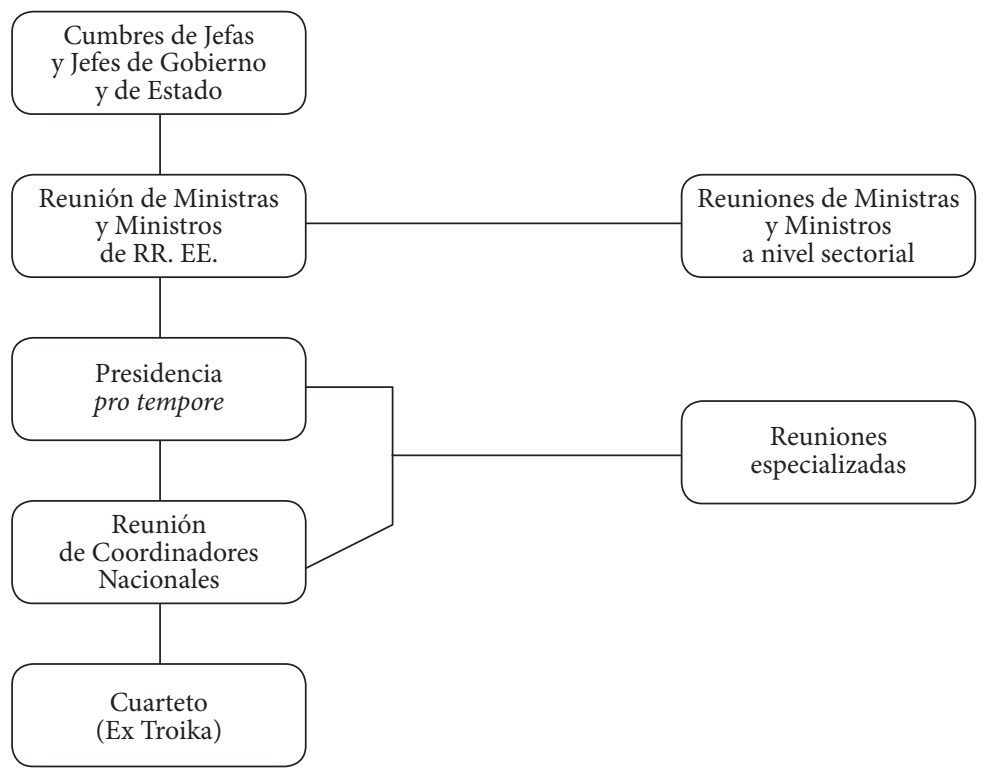

La dimensión político-institucional de los procesos de integración de América Latina (2000-2016)

Alberto Rocha Valencia

\section{Gráfico 8.}

Comunidad de Estados Latinoamericanos y Caribeños (CELAC)

Fuente: elaboración propia. 


\section{Dossier \\ América Latina: \\ continuidad y cambio \\ en el escenario regional}

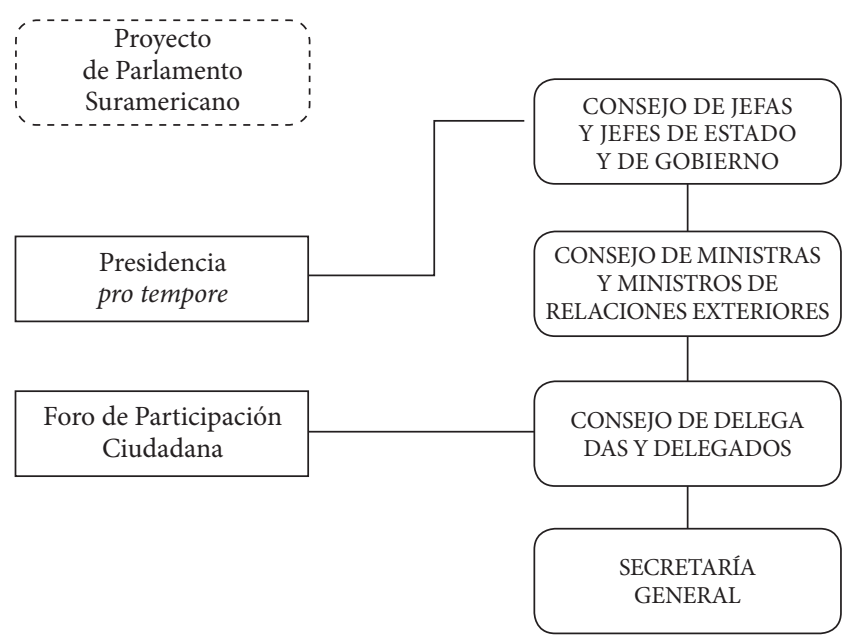

CONSEJOS

- Consejo de Defensa Suramericano de UNASUR

Centro de Estudios

- Consejo Electoral de UNASUR

Estratégicos de Defensa

- Consejo Energético Suramericano

- Consejo Suramericano de Ciencia, Tecnología e Innovación de UNASUR

- Consejo Suramericano de Cultura

- Consejo de Desarrollo Social Suramericano

- Consejo Suramericano de Economía y Finanzas

Banco del Sur

- Consejo Suramericano de Educación

- Consejo de Salud Suramericano de UNASUR

- Consejo Suramericano de Infraestructura y Planeamiento

Gráfico 9.

Unión de Naciones Sudamericanas (UNASUR)

- Consejo Suramericano sobre el Problema Mundial de las Drogas

- Consejo Suramericano en Materia de Seguridad Ciudadana, Justicia y Coordinación de Acciones contra la Delincuencia Organizada Transnacional

Instituto Suramericano de Gobierno en Salud

Fuente: elaboración propia.

Iniciativa para la integración de la Infraestructura Regional Suramericana 


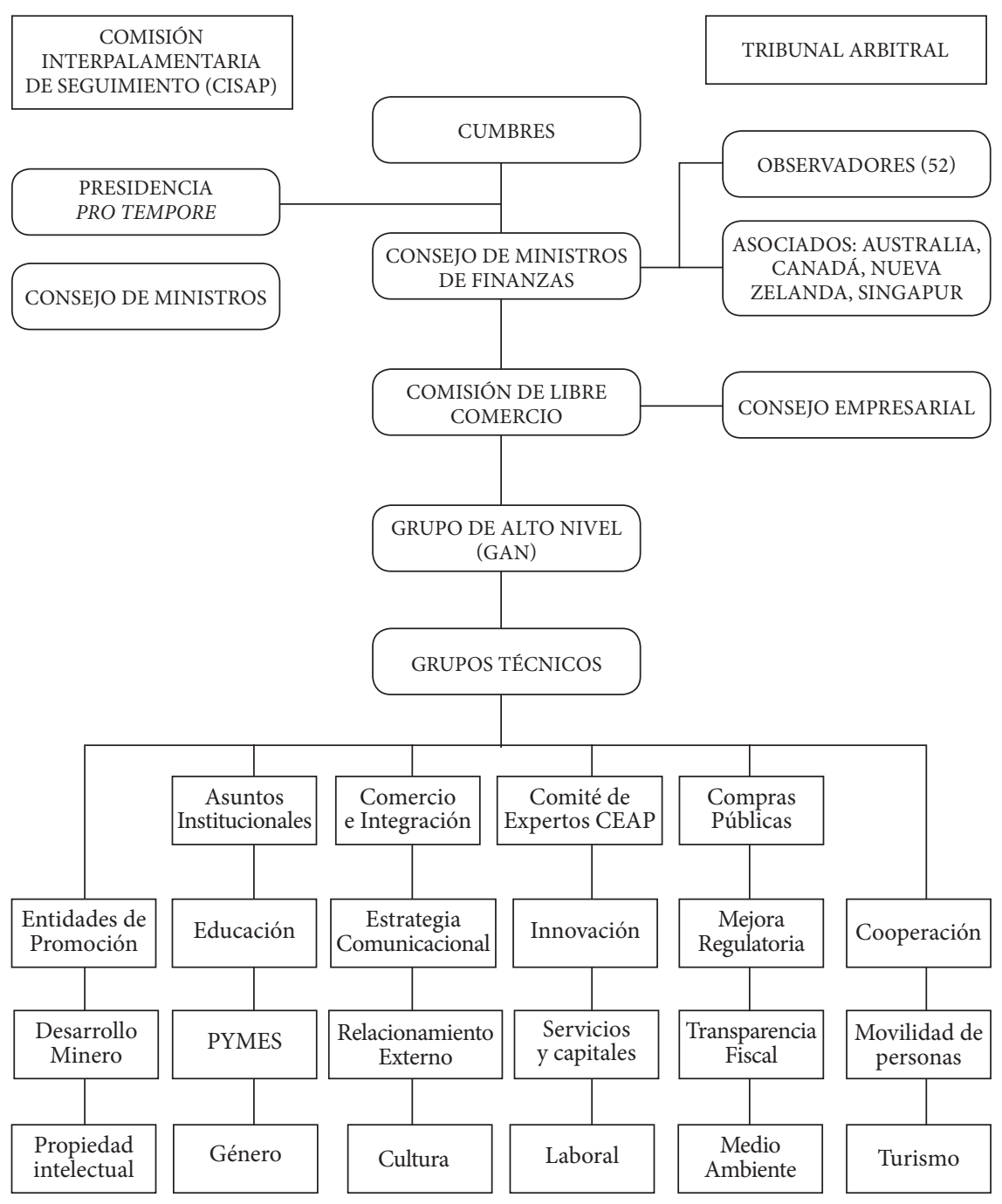

La dimensión político-institucional de los procesos de integración de América Latina (2000-2016)

Alberto Rocha Valencia

\section{Alberto Rocha Valencia}

Gráfico 10.

Alianza del Pacífico (AP)

Fuente: elaboración propia.

\section{Esquemas amplios y complejos: CAN, SICA, CARICOM y MERCOSUR}

En el caso de estos esquemas, la institucionalización es de las más avanzadas y complejas. Existen instituciones económicas, políticas, sociales y culturales, dando lugar a la constitución de importantes subsistemas. Las instituciones políticas de decisión-ejecución (ejecutivas, legislativas y judiciales) son ya centrales y principales y las tecnocracias ya están muy bien establecidas. 
Dossier América Latina: continuidad y cambio en el escenario regional
Las instituciones administrativas se han fortalecido. Las élites políticas gubernamentales nacionales actúan como los actores principales, pero en este caso se encuentran acompañadas de otros actores como las tecnocracias, burocracias, jueces y legisladores. Las instituciones sociales se han logrado conformar y estabilizar y los actores sociales han logrado ganar mayores espacios de participación. Un proceso democrático inicial avanza, en la medida de que se instalan parlamentos subregionales. Aquí nos encontramos con las cuatro Uniones Aduaneras (UA) imperfectas de la región, donde destaca el MERCOSUR y declina la CAN, la que se encuentra en una situación de seria involución y crisis.

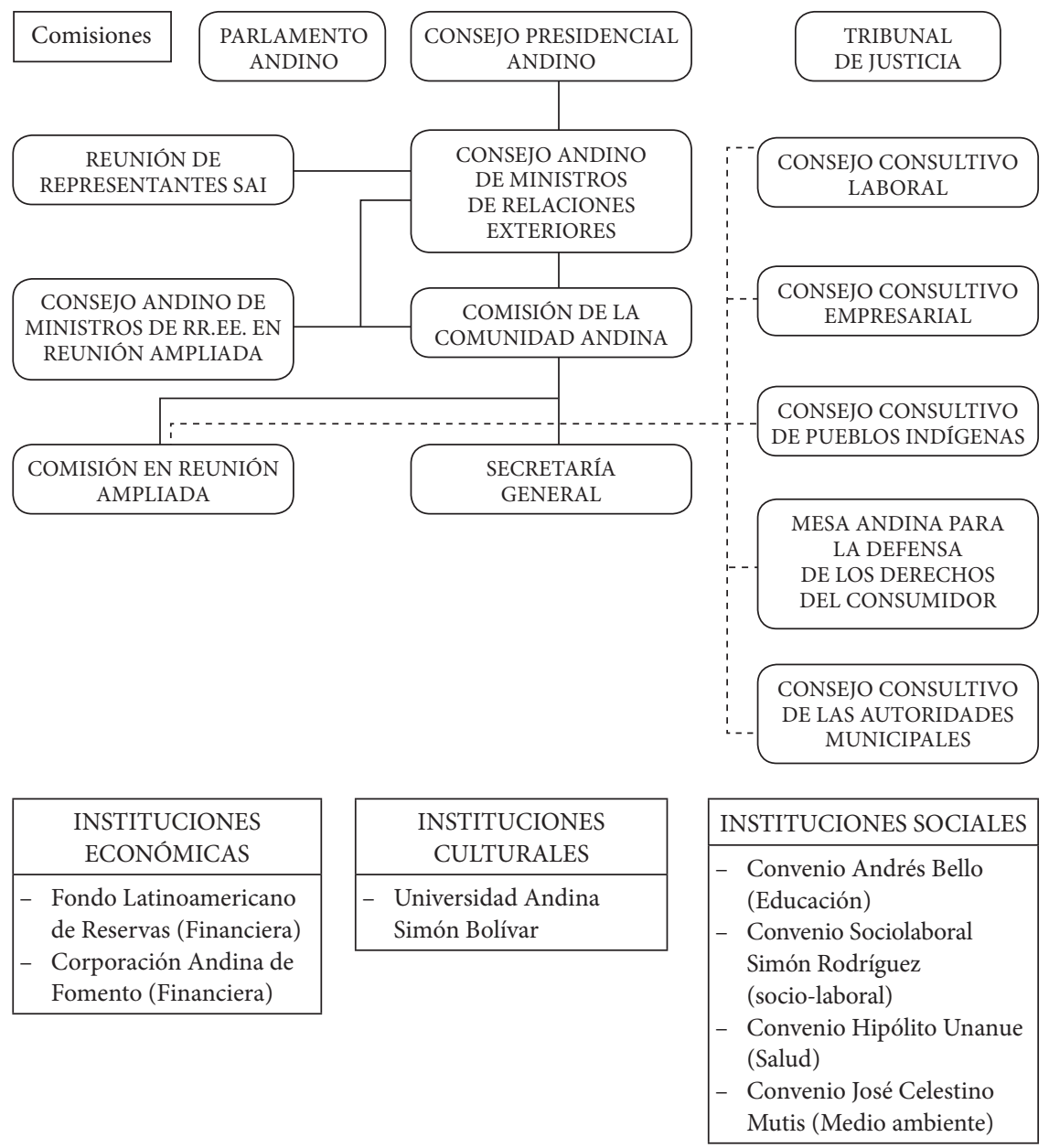

Fuente: elaboración propia.
Gráfico 11.

Comunidad Andina de Naciones (CAN) 


\section{La dimensión \\ político-institucional \\ de los procesos \\ de integración \\ de América Latina \\ (2000-2016)}

Alberto Rocha Valencia

CORTE

CENTROAMERICANA DE JUSTICIA

REUNIÓN DE

VICEPRESIDENTES

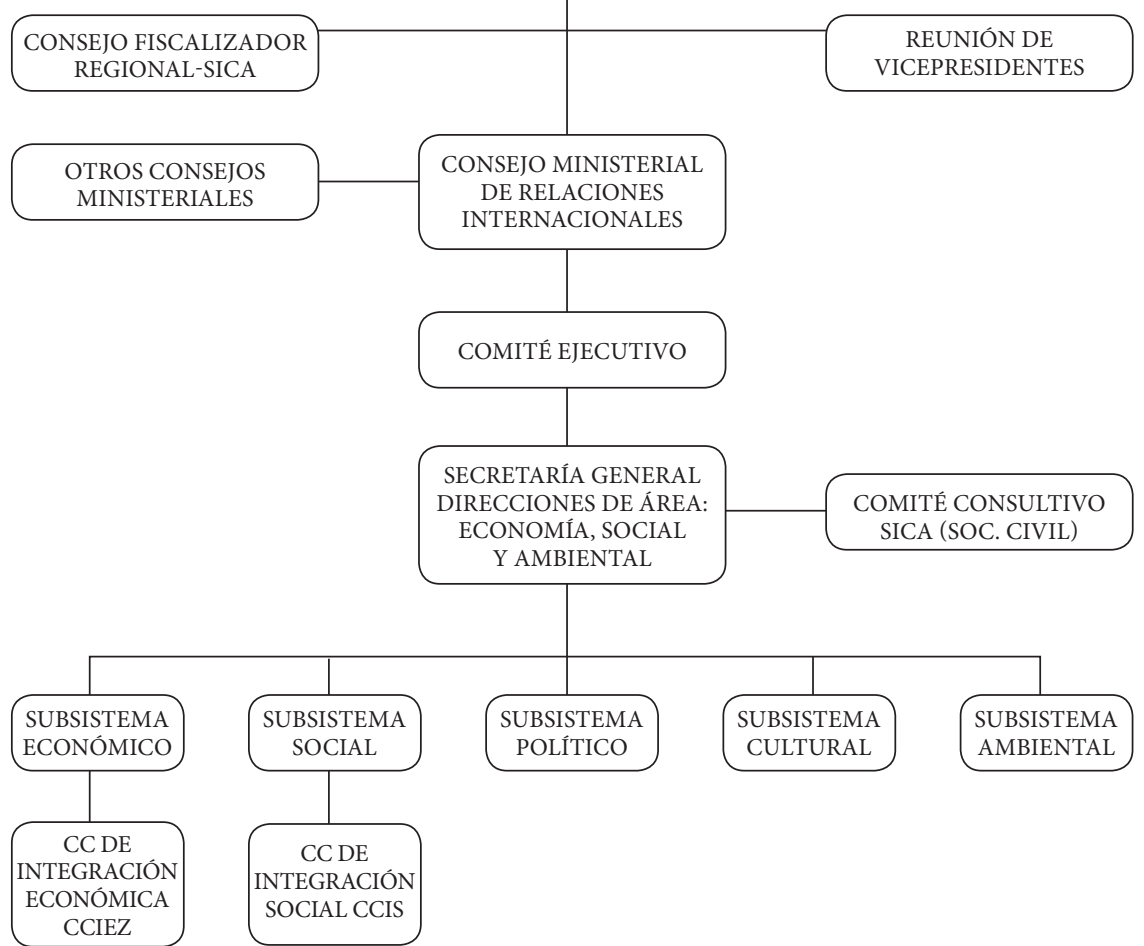

Gráfico 12.

Sistema de Integración Centroamericano (SICA)

Fuente: elaboración propia. 

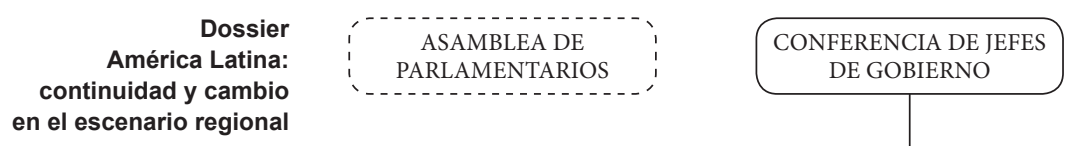

CORTE CARIBEÑA DE JUSTICIA

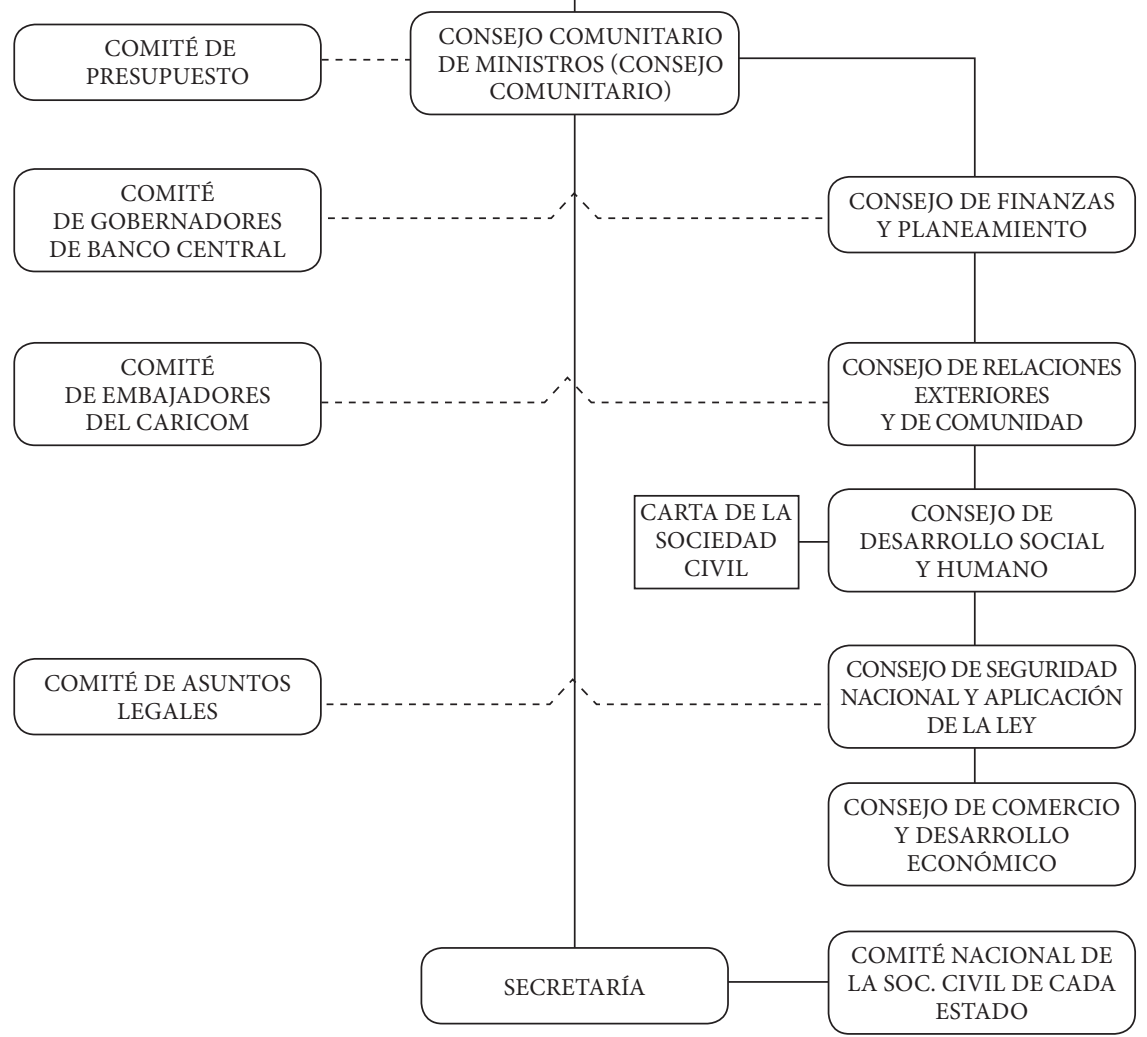

Fuente: elaboración propia. 

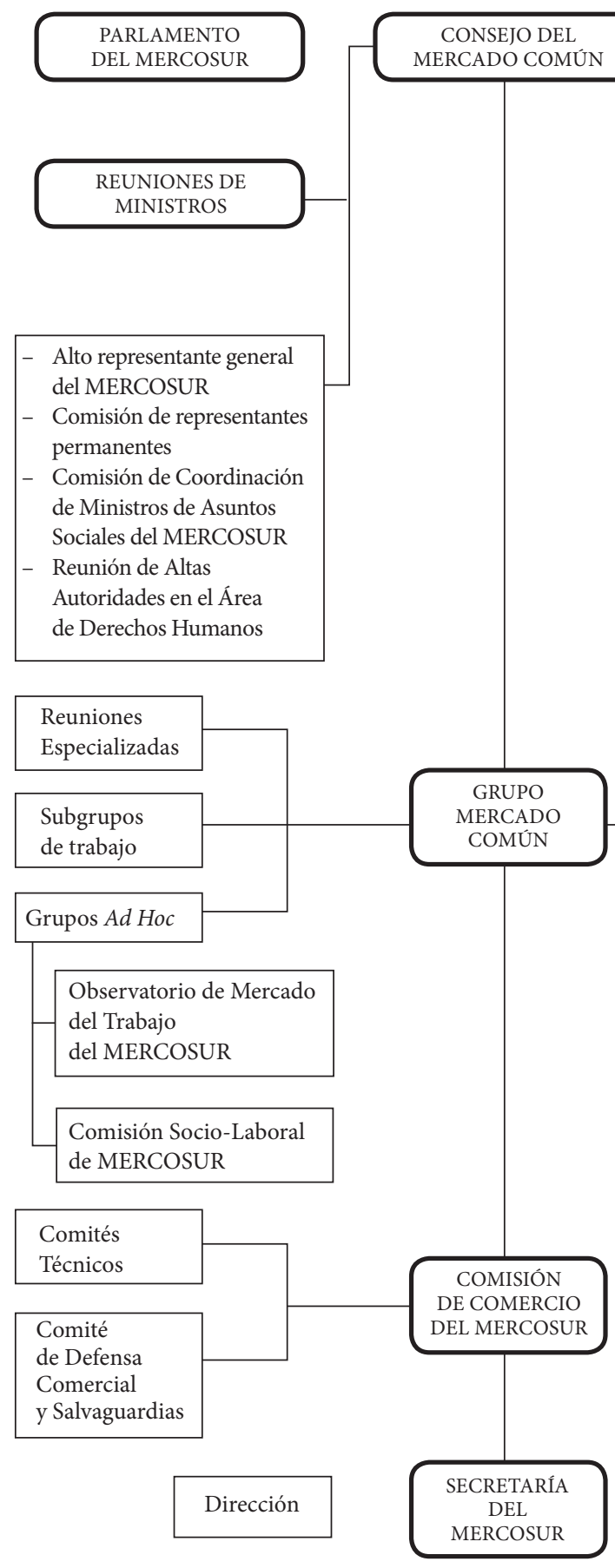

Fuente: elaboración propia.

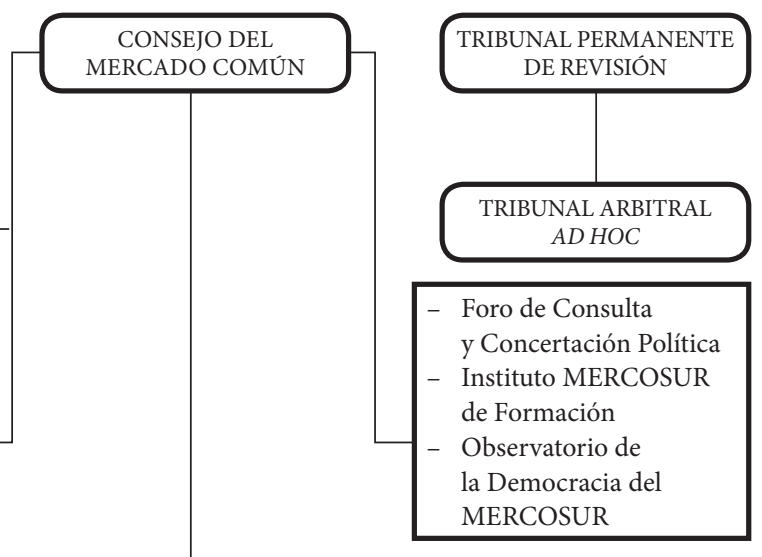

Tribunal Administrativo Laboral

Foro Consultivo de Municipios, Estados Federados, Provincias y Departamentos del MERCOSUR

FORO CONSULTIVO ECONÓMICO-SOCIAL

CENTRO MERCOSUR

DE PROMOCIÓN DE ESTADO DE DERECHO

Instituto Social del MERCOSUR

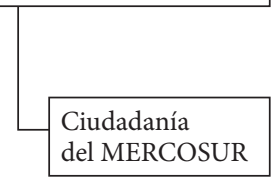

La dimensión político-institucional de los procesos de integración de América Latina (2000-2016)

Alberto Rocha Valencia
Gráfico 14.

Mercado Común del Sur (MERCOSUR) 
Dossier América Latina: continuidad y cambio en el escenario regional

\section{Clasificación de las dimensiones político-institucionales de los procesos de integración regional y subregional de acuerdo con sus cuadros de análisis político-institucional}

Sobre la base de la clasificación anterior, ahora proponemos una clasificación en cuatro categorías de formas político-institucionales. La primera clasificación se hizo teniendo como referencia los organigramas de cada uno de los procesos de integración, la segunda clasificación se hará a partir de los cuadros de análisis político-institucional de cada uno de ellos.

Como podemos ver este trabajo pone mucho énfasis en la dimensión institucional de los procesos de integración regional y subregional, esto debido a que compartimos la visión anotada por el SELA sobre el rol de las instituciones en los procesos de integración regional:

Los estudios empíricos sugieren que la institucionalidad es clave para el desarrollo de la integración regional (SELA 2004). De esta forma, aunque los esfuerzos puedan tardar muchos años en rendir los frutos deseados, se requiere de un profundo compromiso político que tenga como objetivo fortalecer lo que se ha llamado "integración institucional” (SELA 2018: 3).

Veamos la siguiente clasificación:

Forma político-institucional simple: TLC México-Colombia y TLC México-Chile

Los procesos de integración son unidimensionales y eminentemente comerciales. Las formas son muy simples y las instituciones son elementales e intergubernamentales. En estas formas se practica una gobernanza llana, pues la dirección política viene de afuera, esto es de los gobiernos nacionales.

Forma político-institucional relativamente avanzada: ALBA, AEC y PIM Estos procesos de integración son multidimensionales, aunque muy acotados. Las formas están conformadas por instituciones más numerosas y un poco más constituidas y son fundamentalmente intergubernamentales. Solamente en el ALBA se promueve la participación inicial de los actores sociales. En esta forma se practica una gobernanza intensa (la toma de decisiones viene de los gobiernos nacionales) a la que se le añaden rasgos de una gobernabilidad germinal (ya se contempla la formalidad de reuniones presidenciales).

Forma político-institucional avanzada y dinámica: CELAC, UNASUR y AP Los procesos de integración son multidimensionales, aunque todavía un poco limitados. En estas formas las instituciones son más numerosas, consolidadas y plenamente intergubernamentales. Las instituciones políticas y las élites gubernamentales ya se están instalando en el centro del esquema institucional. 


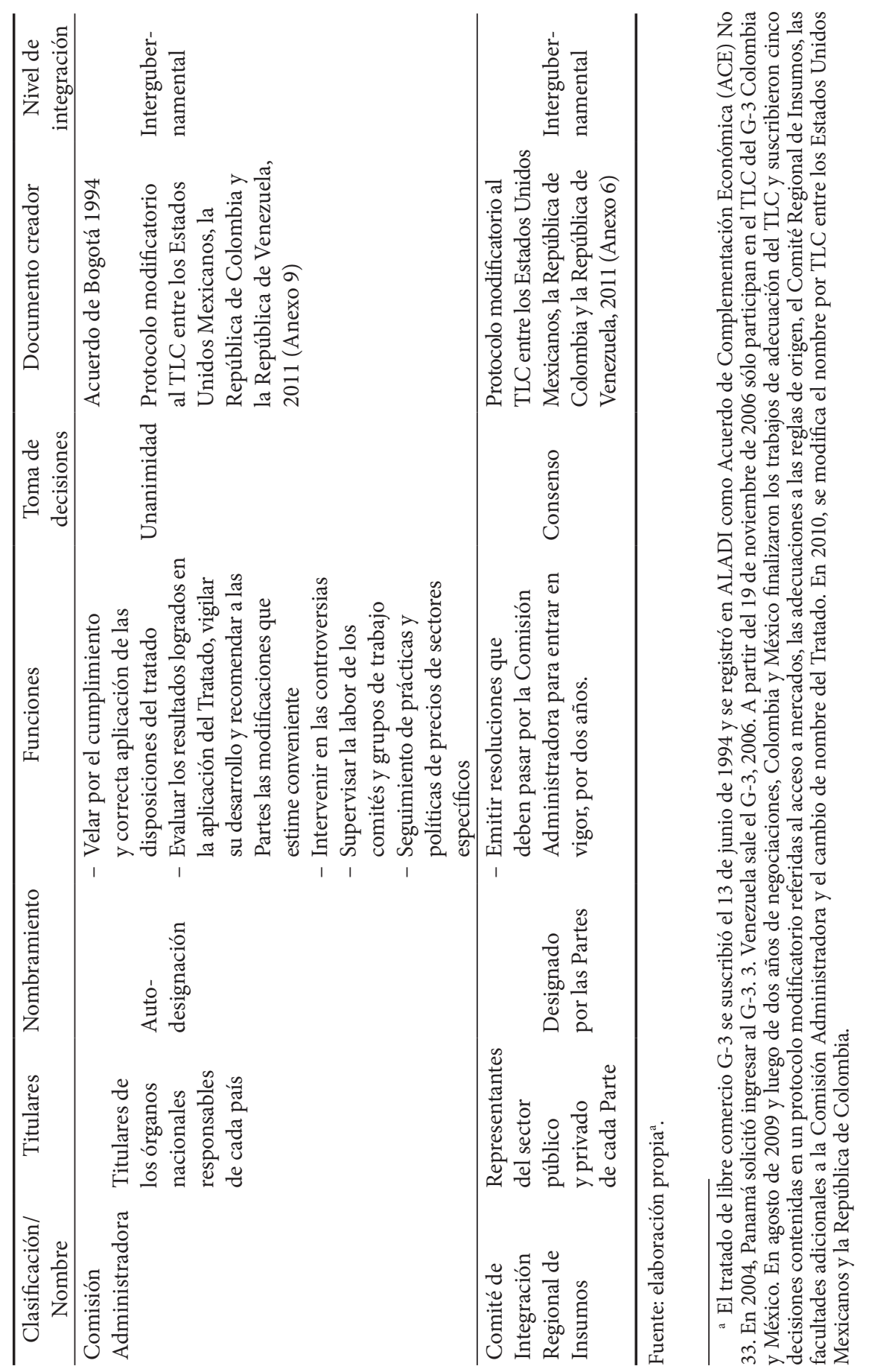

La dimensión político-institucional de los procesos de integración de América Latina (2000-2016)

Alberto Rocha Valencia

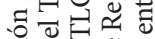

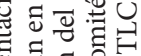

总:

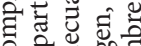

을윰응

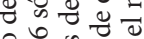

유ㅇㅠㅠ

บृ

ํํㅇำ

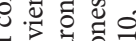

․ㅗำ워ำ

号芆司

궁

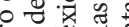

光战

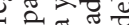

४

ㅇํㅇ छี

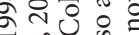

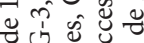

으응 $\frac{\pi}{\pi}$

离䒕氜

व

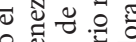

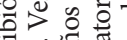

पें '⿱一兀)

ஸे

Alberto Rocha Valencia




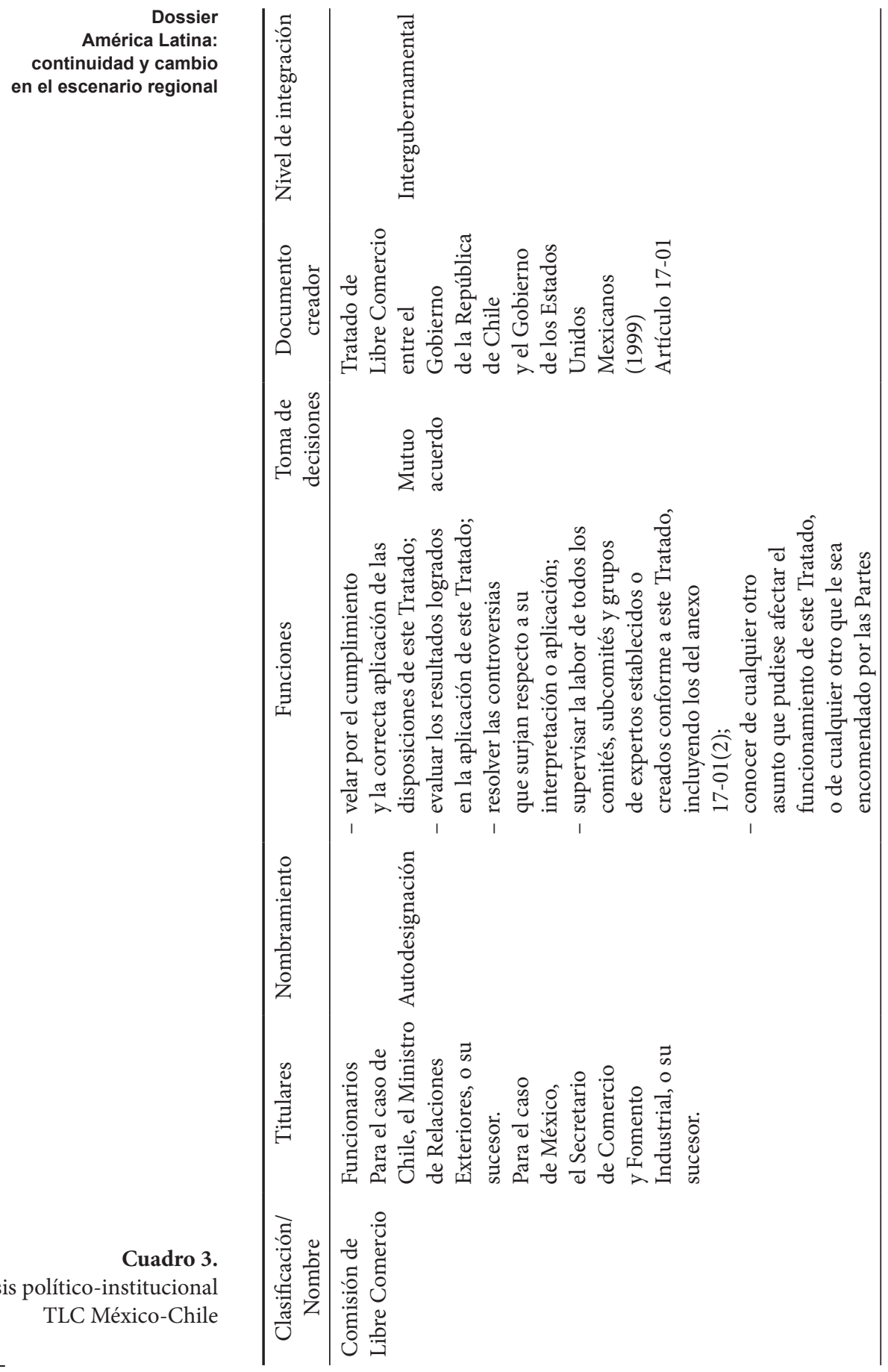




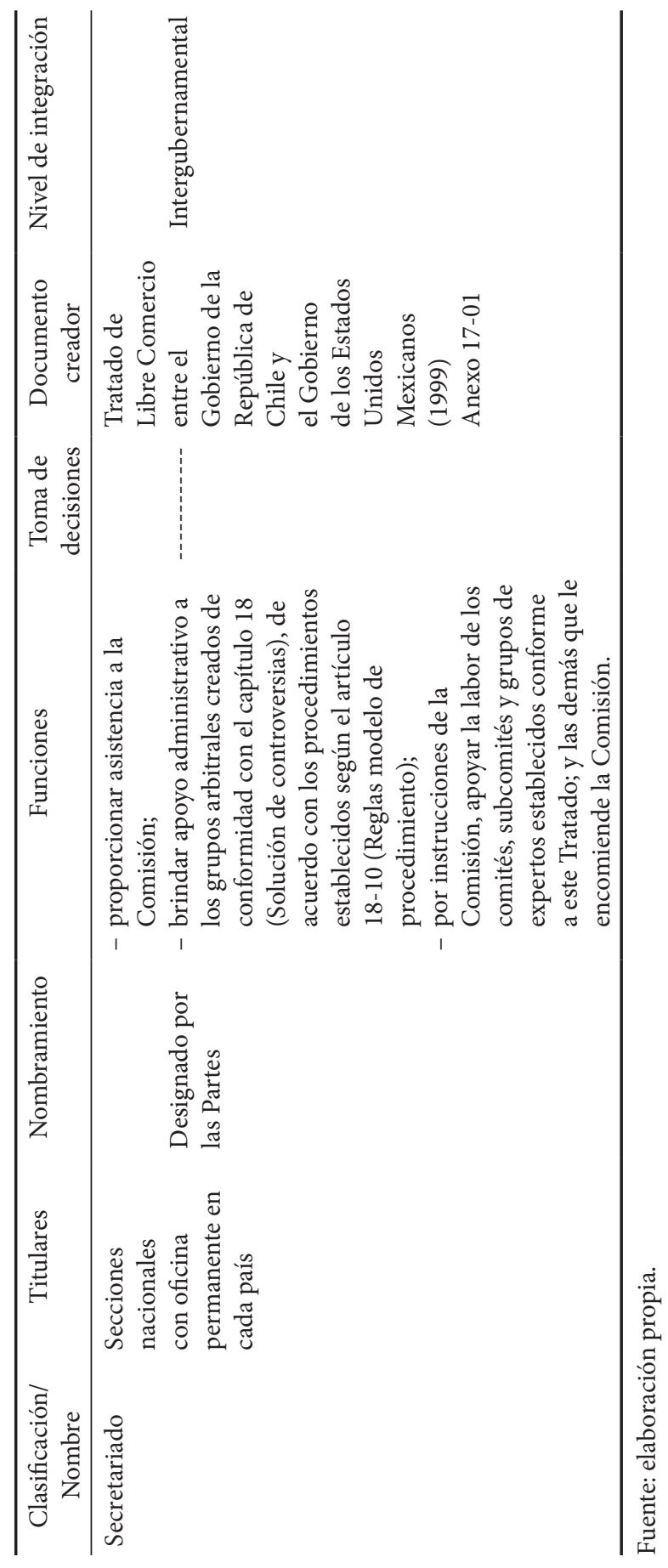

\author{
La dimensión \\ político-institucional \\ de los procesos \\ de integración \\ de América Latina \\ (2000-2016)
}

Alberto Rocha Valencia
Cuadro 3. continuado 


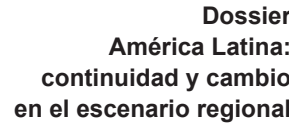

Cuadro 4

Análisis político-institucional de la ALBA-TCP

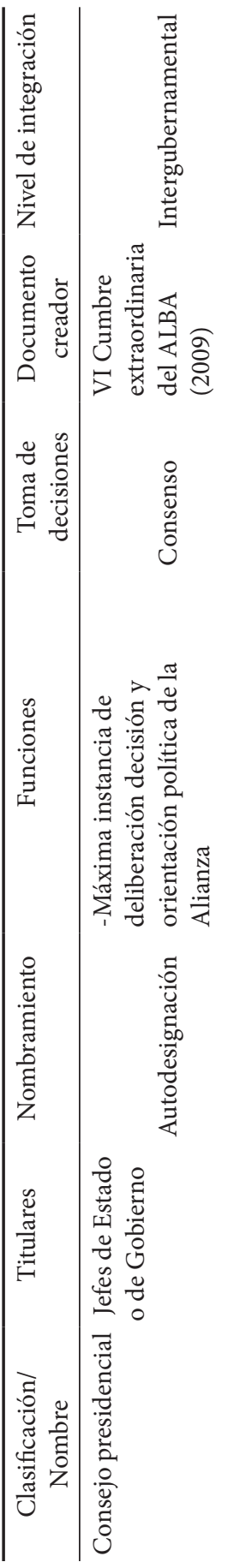

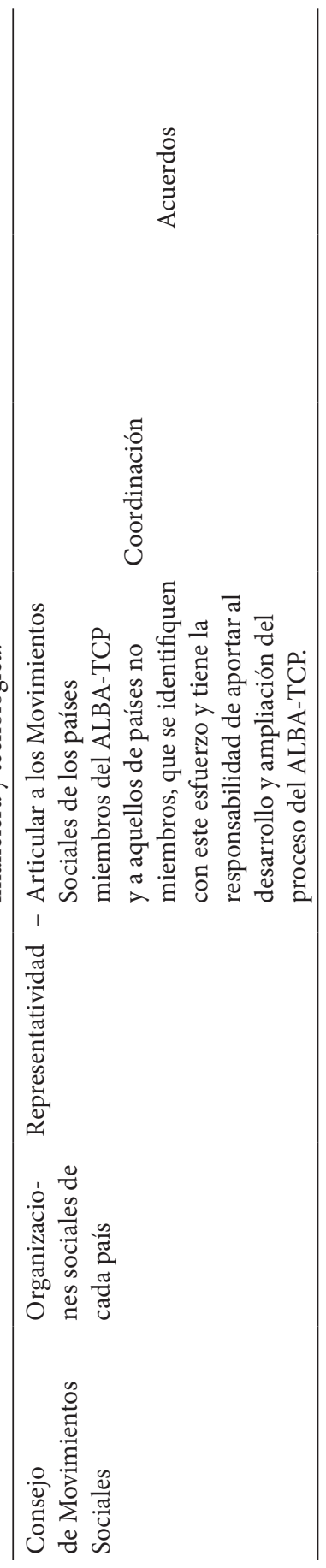




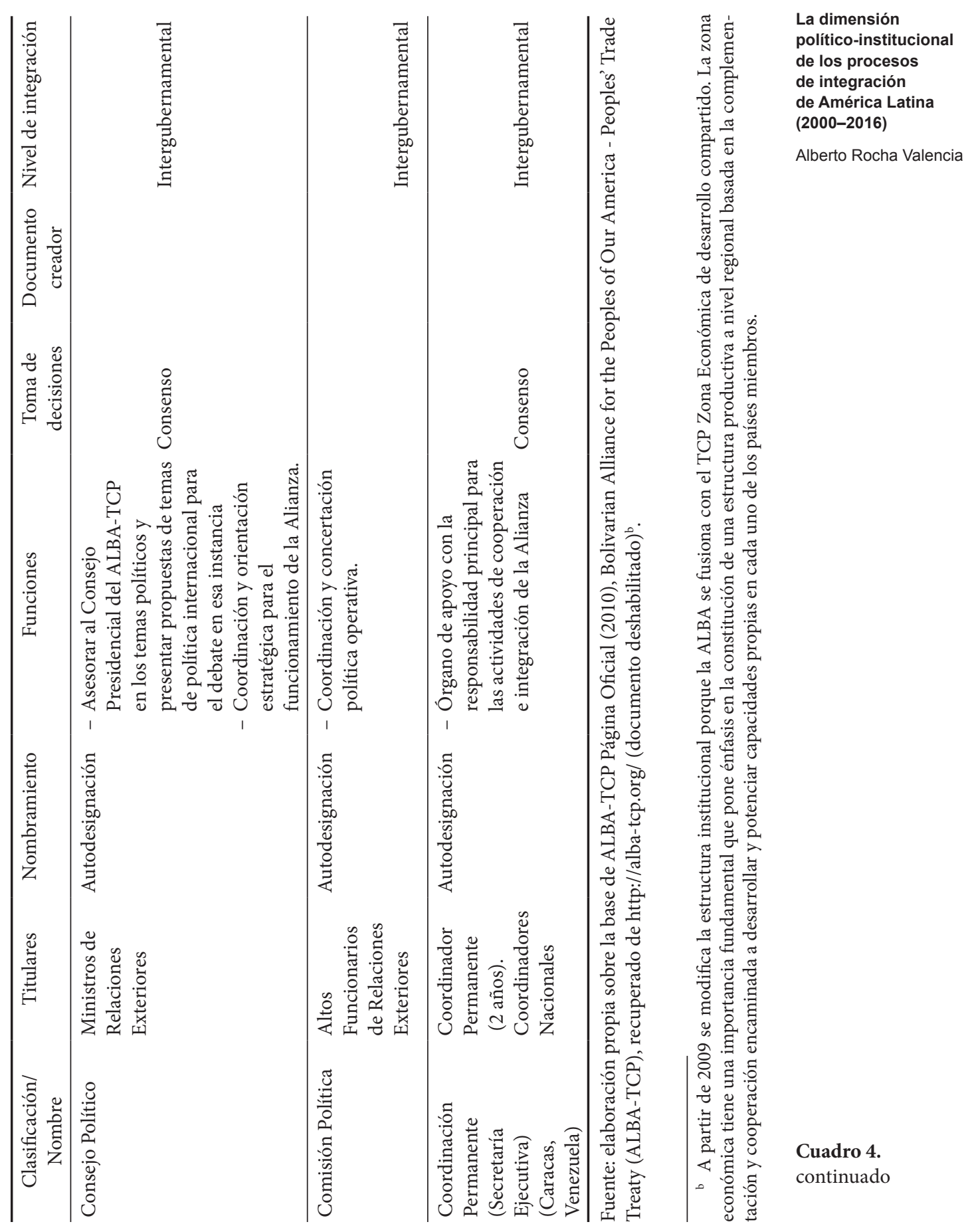



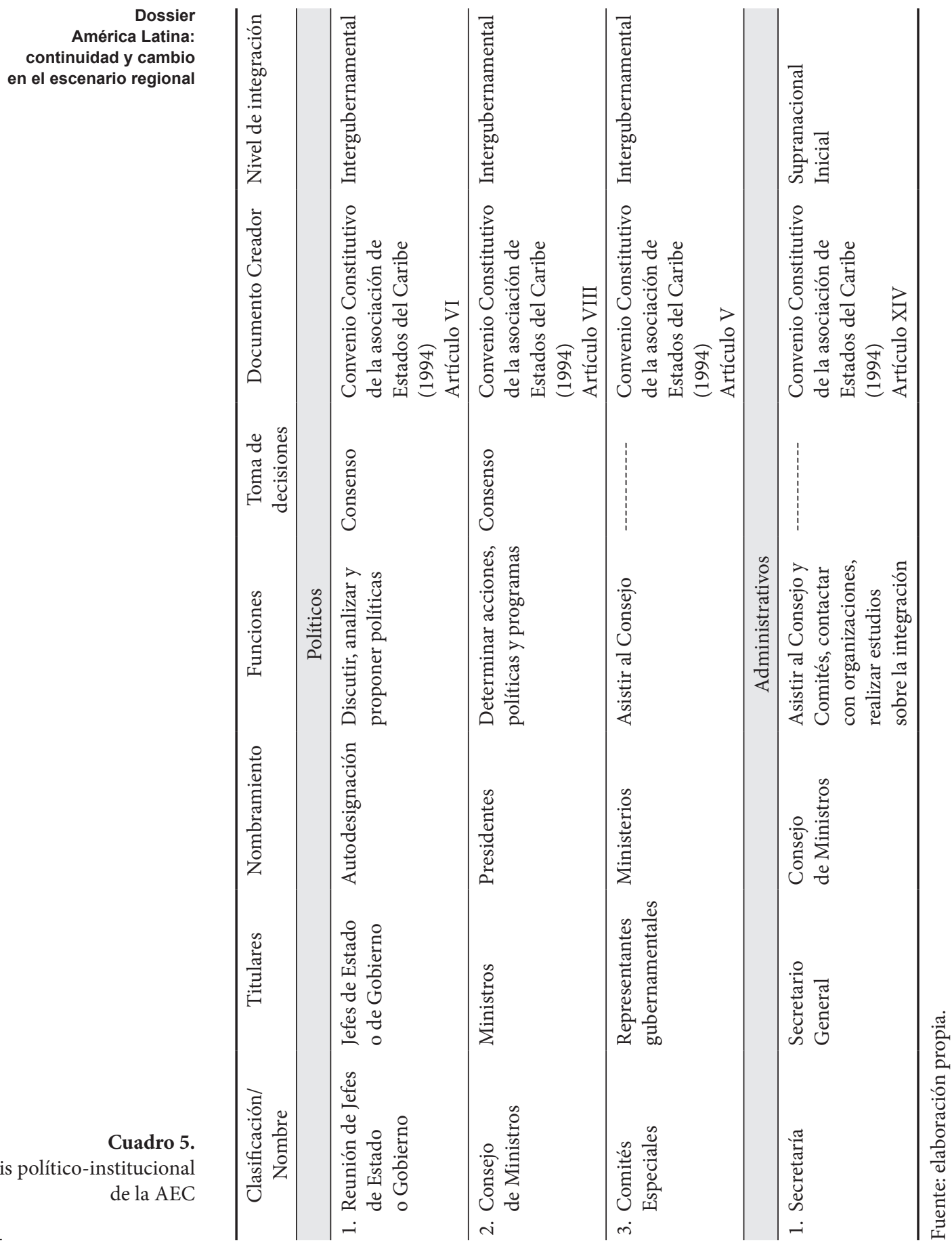


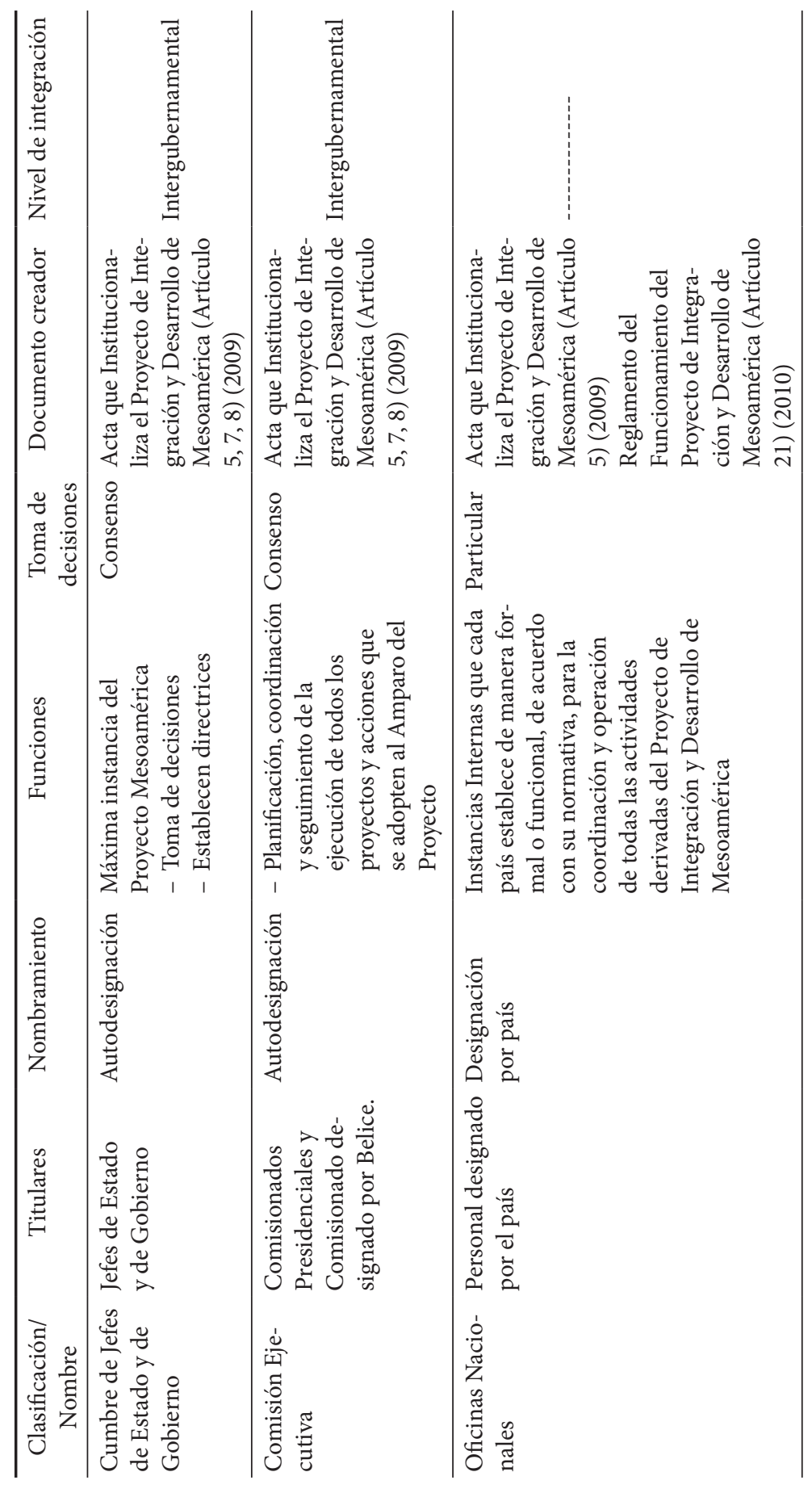

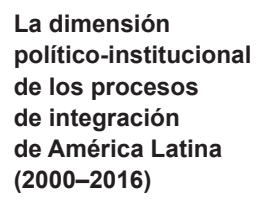

Alberto Rocha Valencia
Cuadro 6.

Análisis político-institucional del PM 


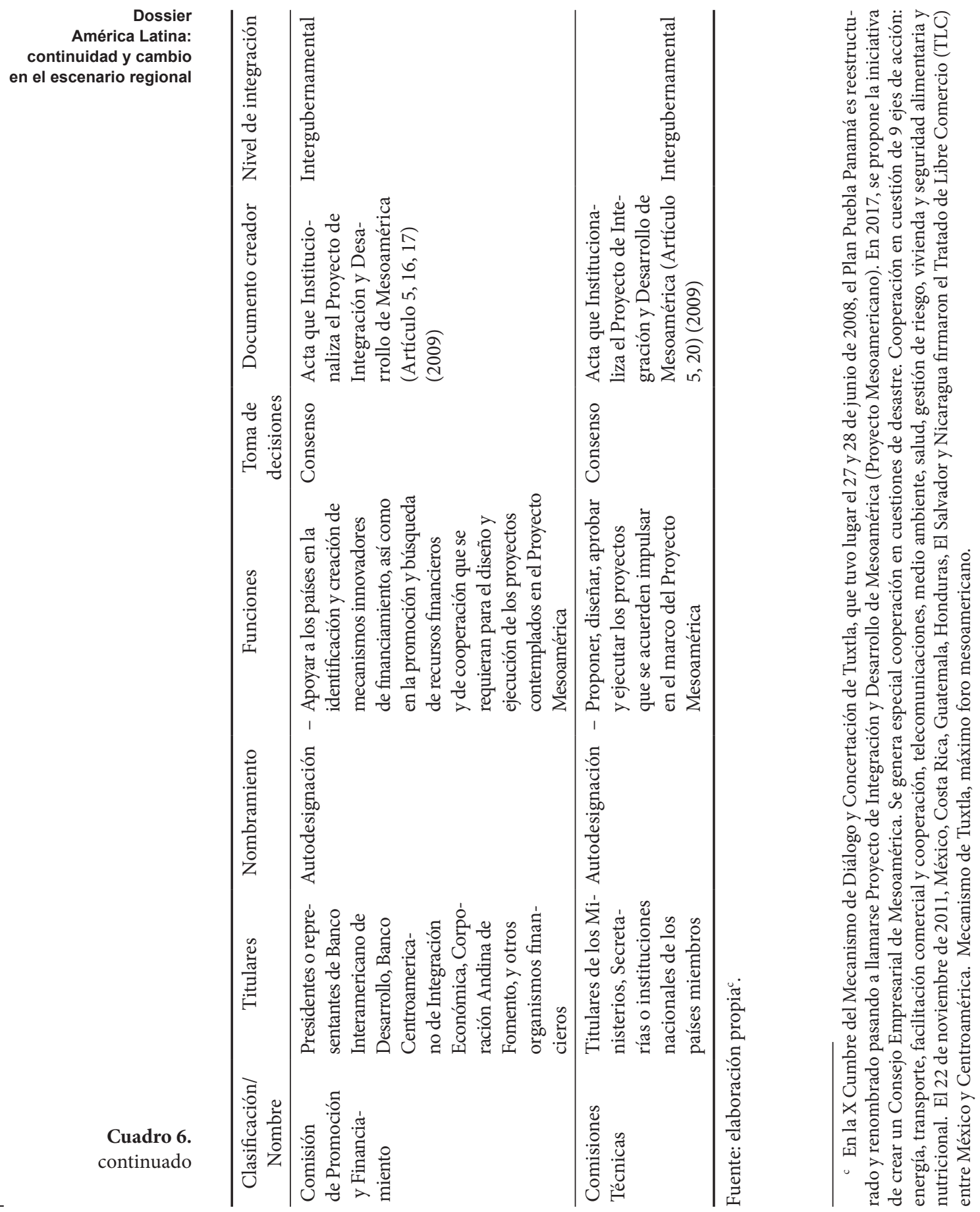




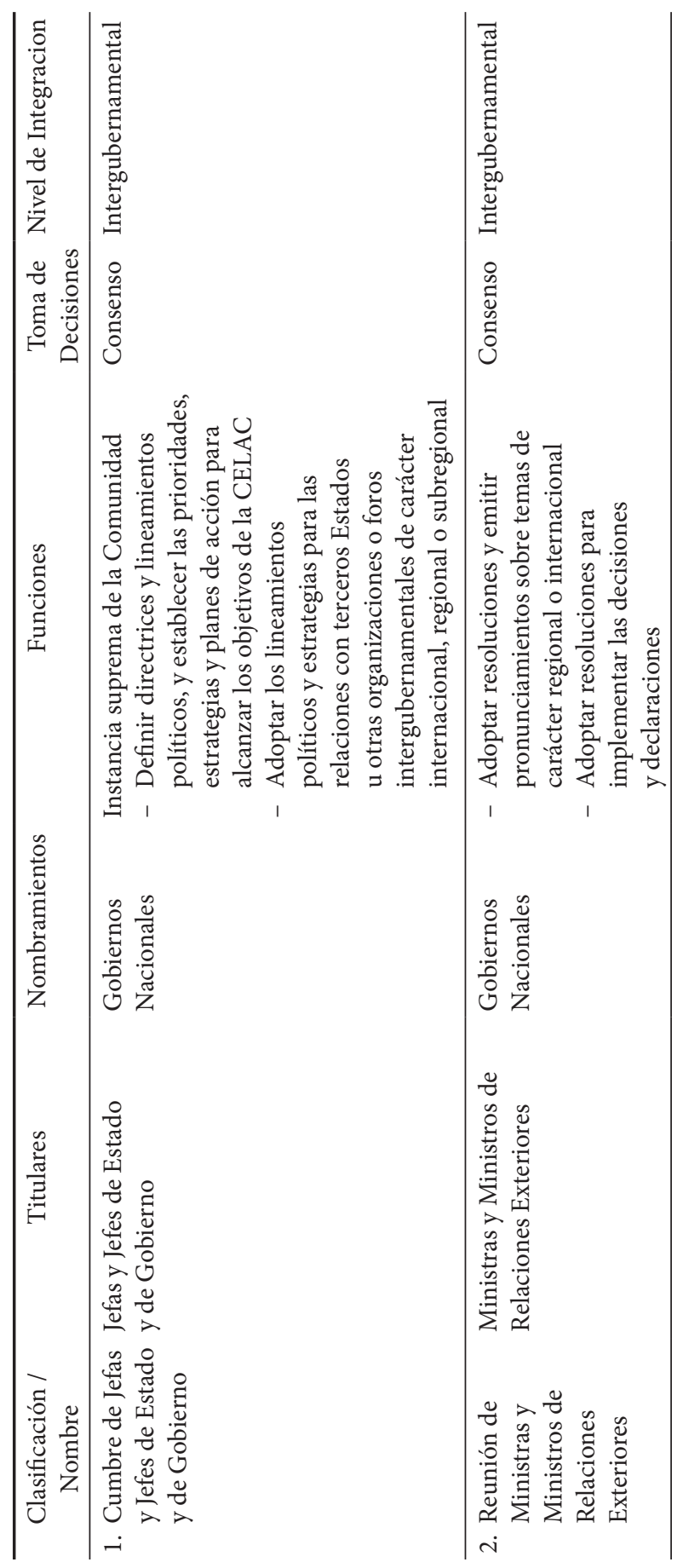

\section{La dimensión político-institucional de los procesos de integración de América Latina (2000-2016)}

Alberto Rocha Valencia

Cuadro 7.

Análisis político-institucional de la CELAC 


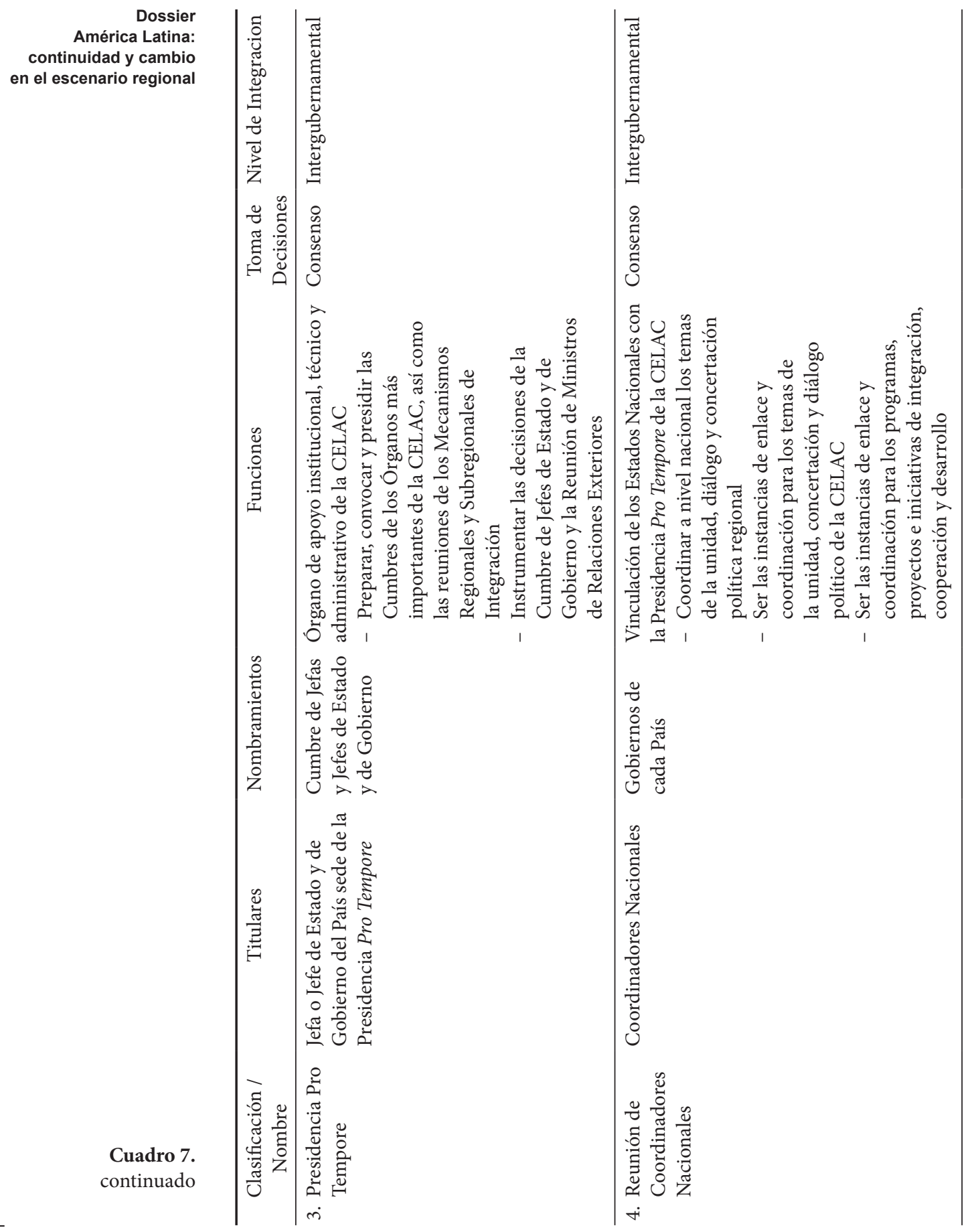



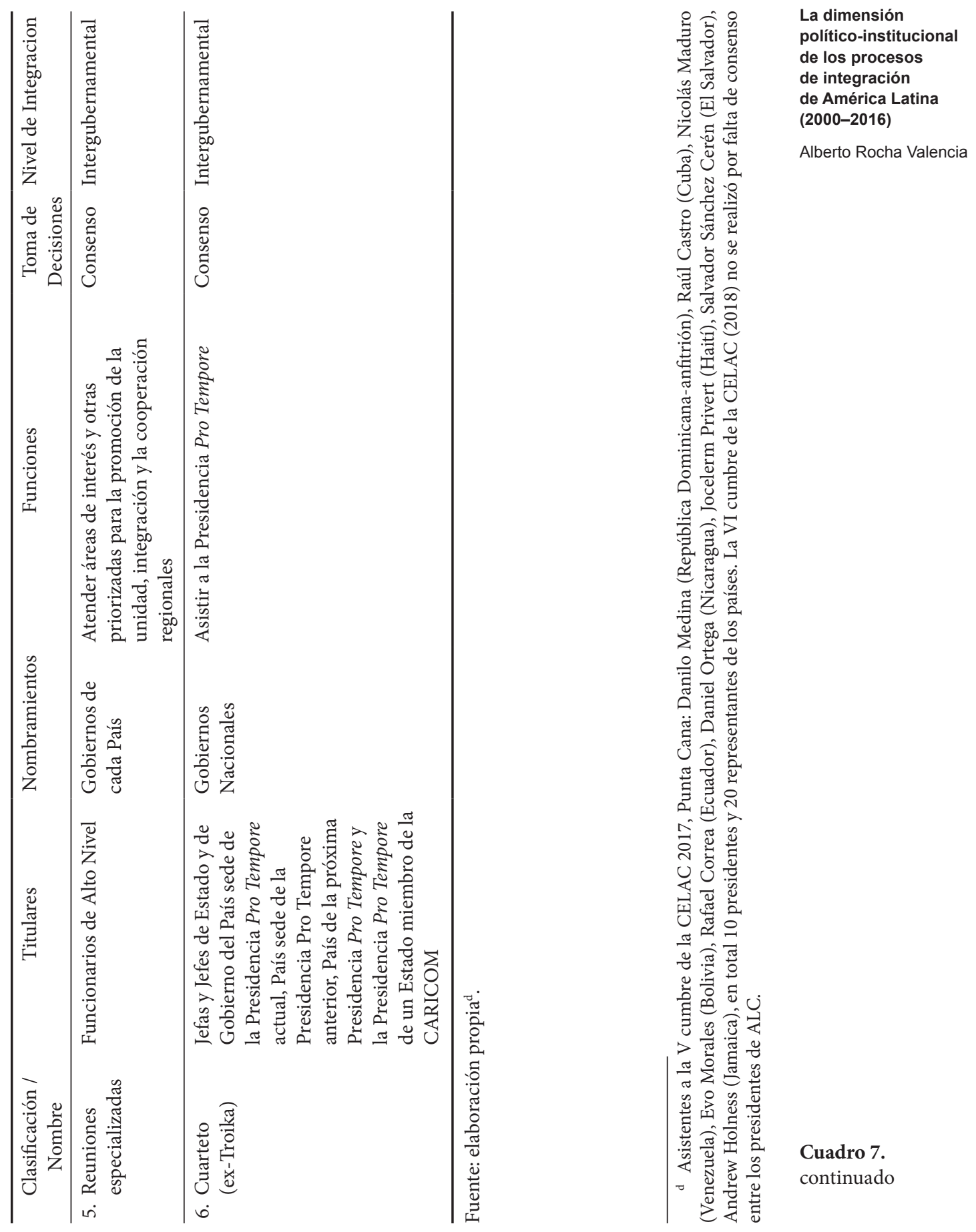


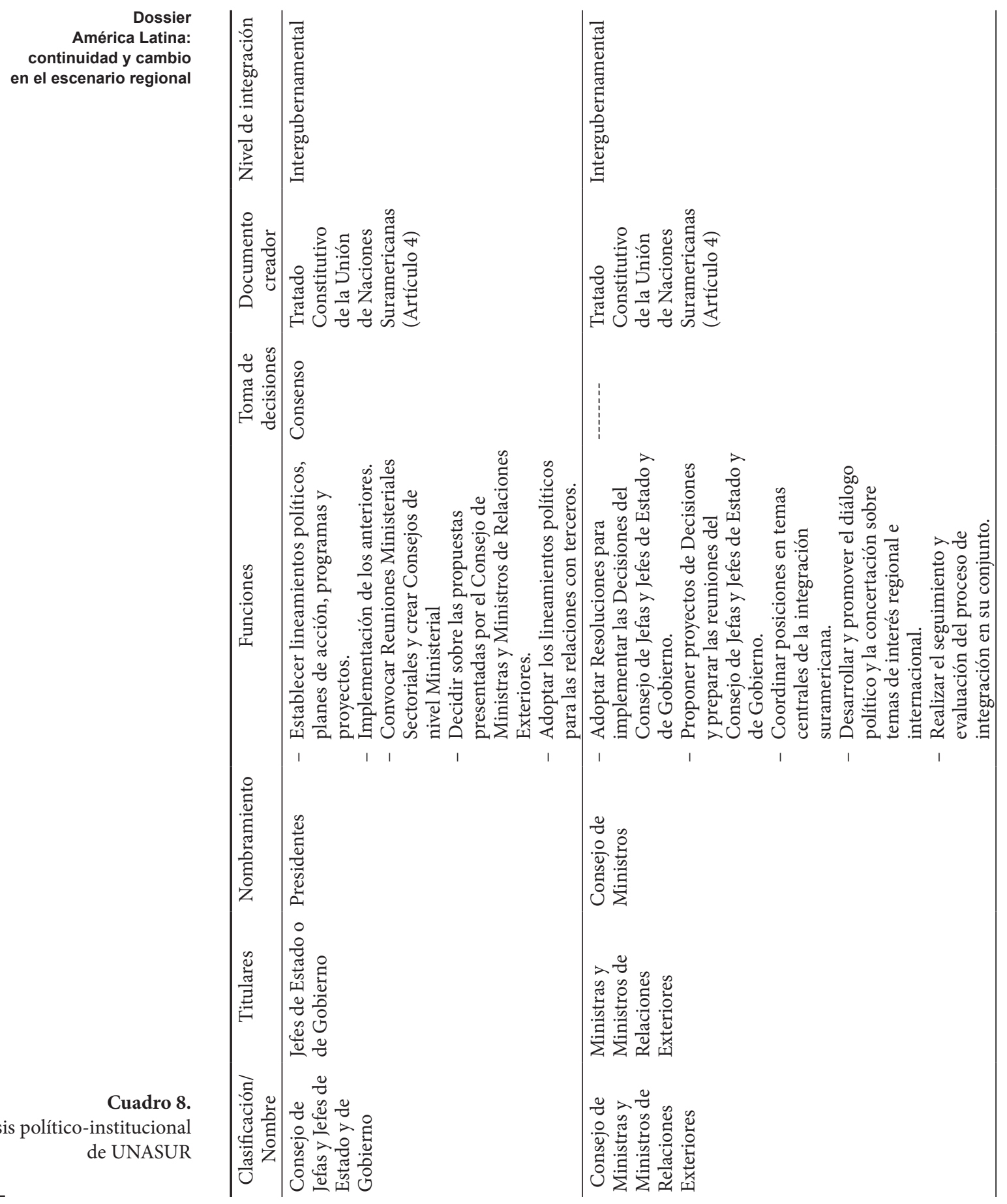




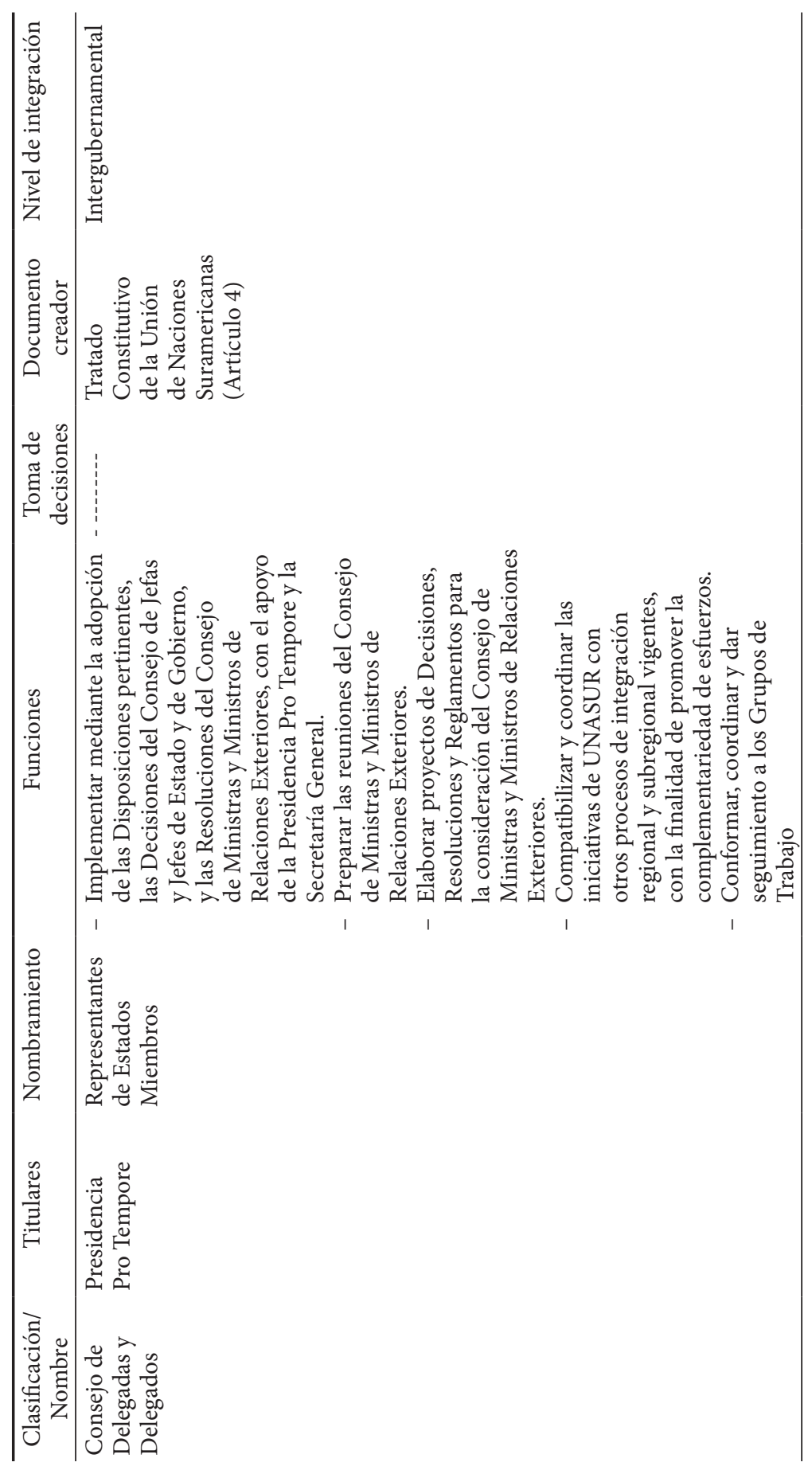

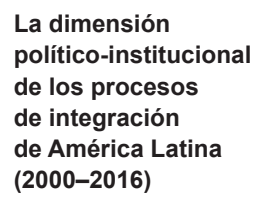

Alberto Rocha Valencia

Cuadro 8.

continuado 


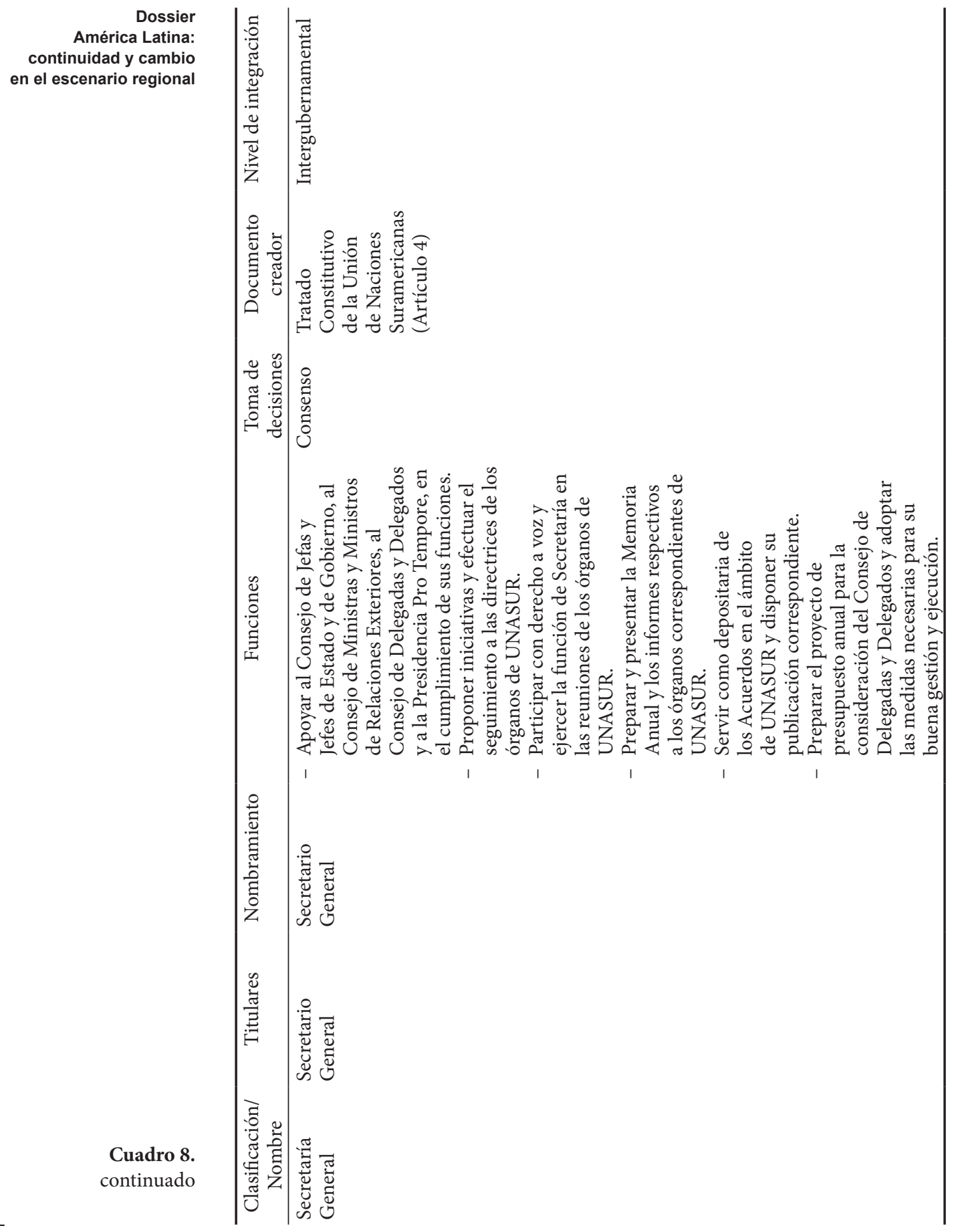




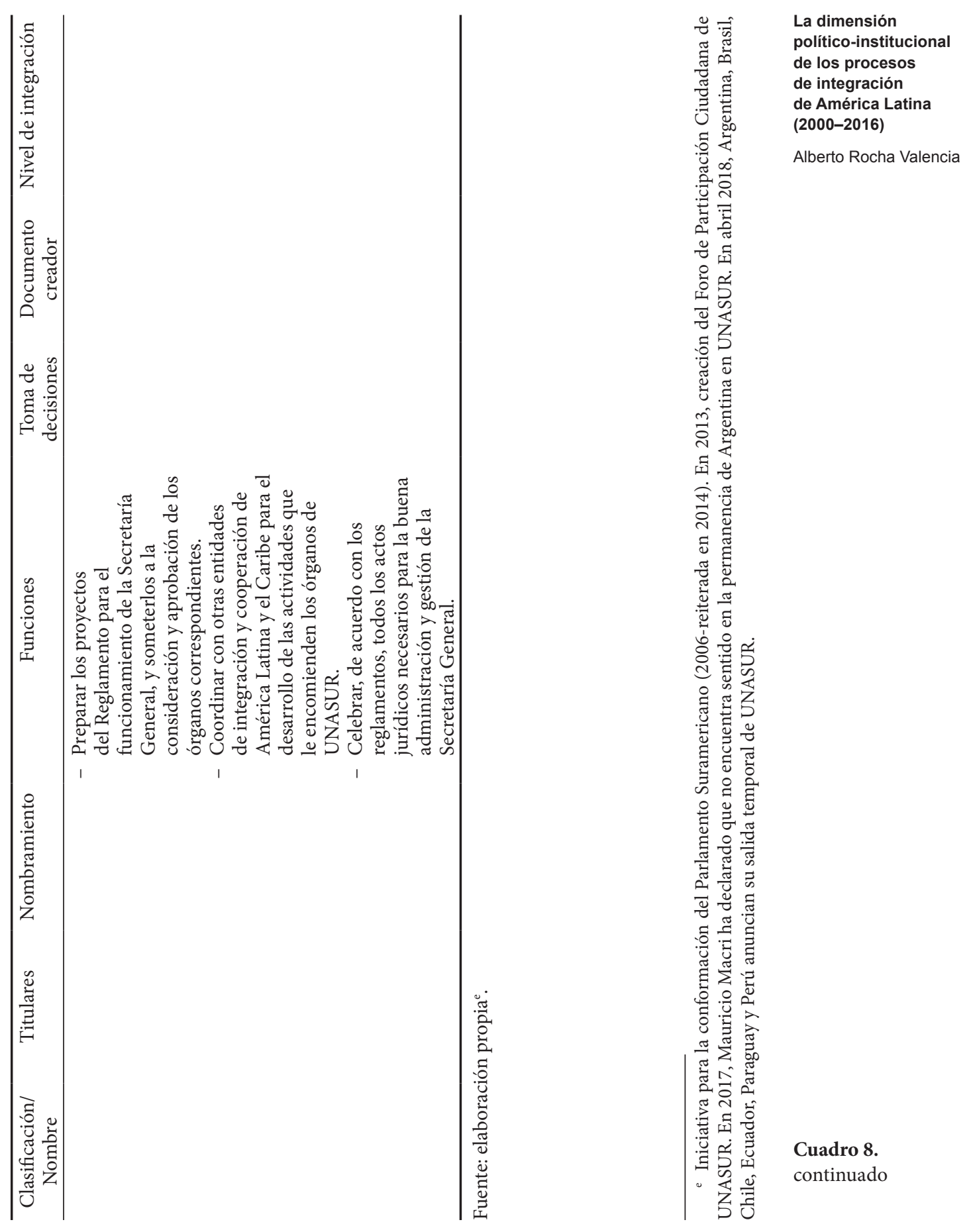




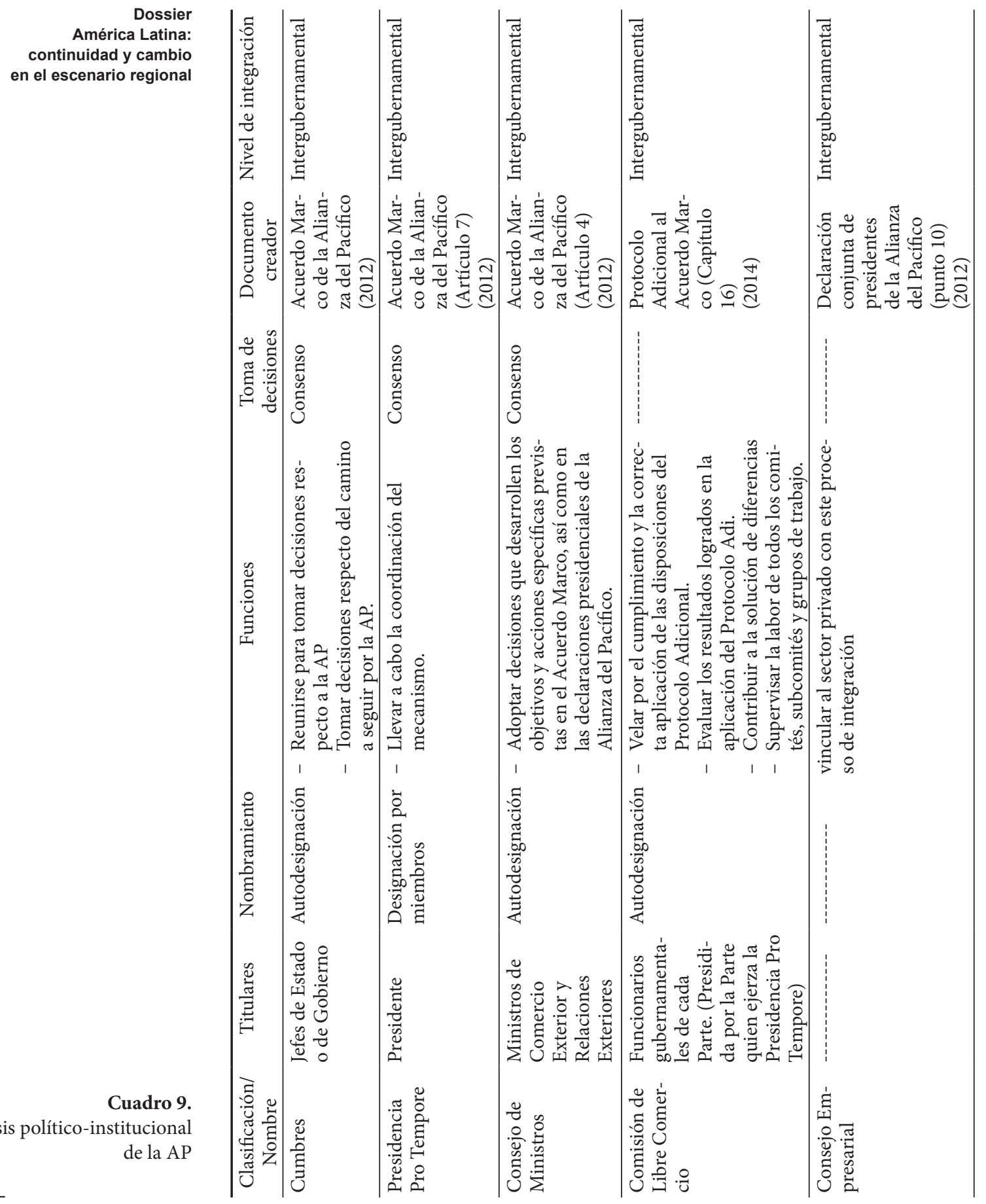




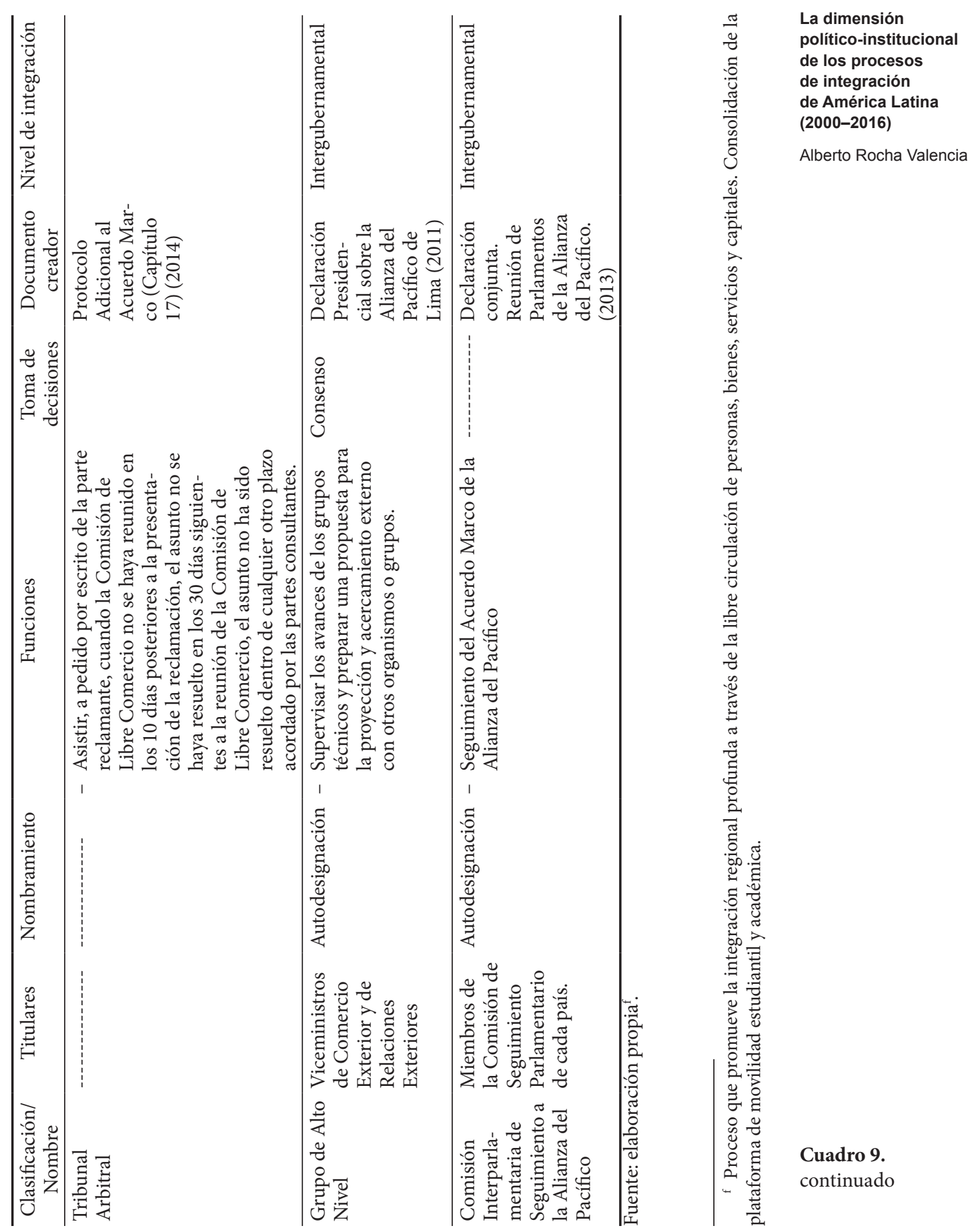


Dossier América Latina: continuidad y cambio en el escenario regional
Las instituciones sociales son iniciales y comienzan a propiciar la participación de los actores sociales, sobre todo en la UNASUR y la AP. La práctica de la gobernanza es fuerte (debido a la intergubernamentalidad, aunque en la Secretaría General de la UNASUR se intentó plasmar un rasgo mínimo de supranacionalidad) y complementada por un ejercicio de gobernabilidad creciente (las reuniones presidenciales, de ministros y de otras autoridades se encuentran debidamente instaladas).

\section{Forma político-institucional amplia y compleja: CAN, SICA, CARICOM y MERCOSUR}

Los procesos de integración disponen de una multidimensionalidad amplia (están presentes y constituidas cuatro dimensiones) y compleja (hay complementariedad y retroalimentación entre las dimensiones). Las instituciones son mucho más numerosas, más consolidadas y cubren todas las dimensiones; entre las instituciones políticas ya están presentes las necesarias (ejecutivo, legislativo y judicial) y con funciones bastante definidas. Algunas instituciones políticas abordaron el nivel de la supranacionalidad: parlamentos, cortes y tribunales de justicia, así como las secretarías administrativas. Las instituciones sociales se transformaron en consejos, comités y foros para la participación de la sociedad civil. La práctica de la gobernabilidad está claramente establecida, pues en cada una de estas dimensiones se produce dirección política y gobernanza. La excepción es la CAN por su involución. En estos casos, la gobernabilidad es un proceso donde interactúan las instituciones políticas ejecutiva, legislativa y judicial, las instituciones sociales y la misma sociedad civil. En estos procesos subregionales se impulsaron procesos democráticos para la elección de los parlamentos respectivos, siendo los más avanzados en el MERCOSUR, el SICA y la CAN (ahora en plena involución), pero en menor medida en la CARICOM. 


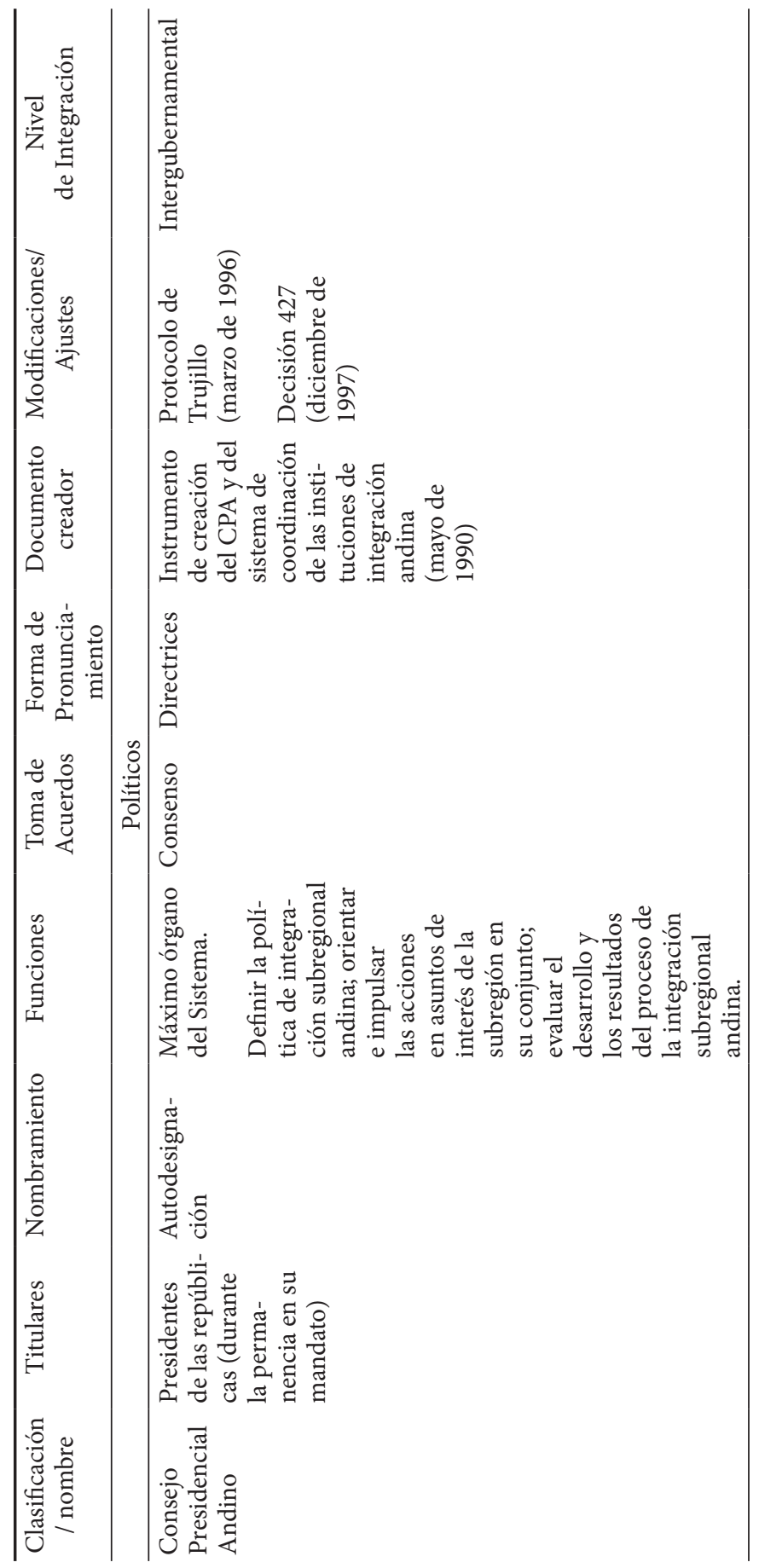

\section{La dimensión político-institucional de los procesos de integración de América Latina (2000-2016)}

Alberto Rocha Valencia

Cuadro 10.

Análisis político-institucional de la CAN 


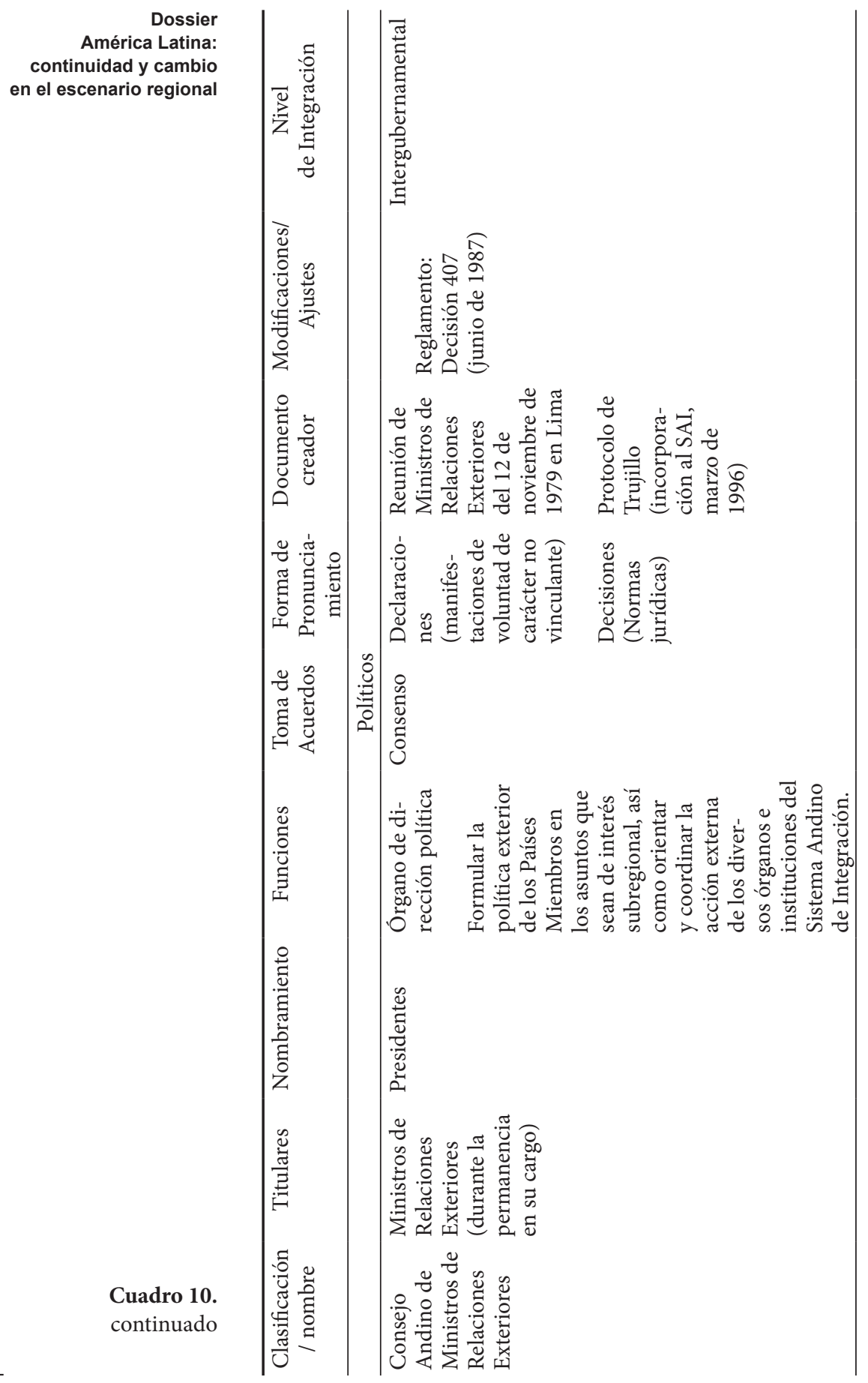




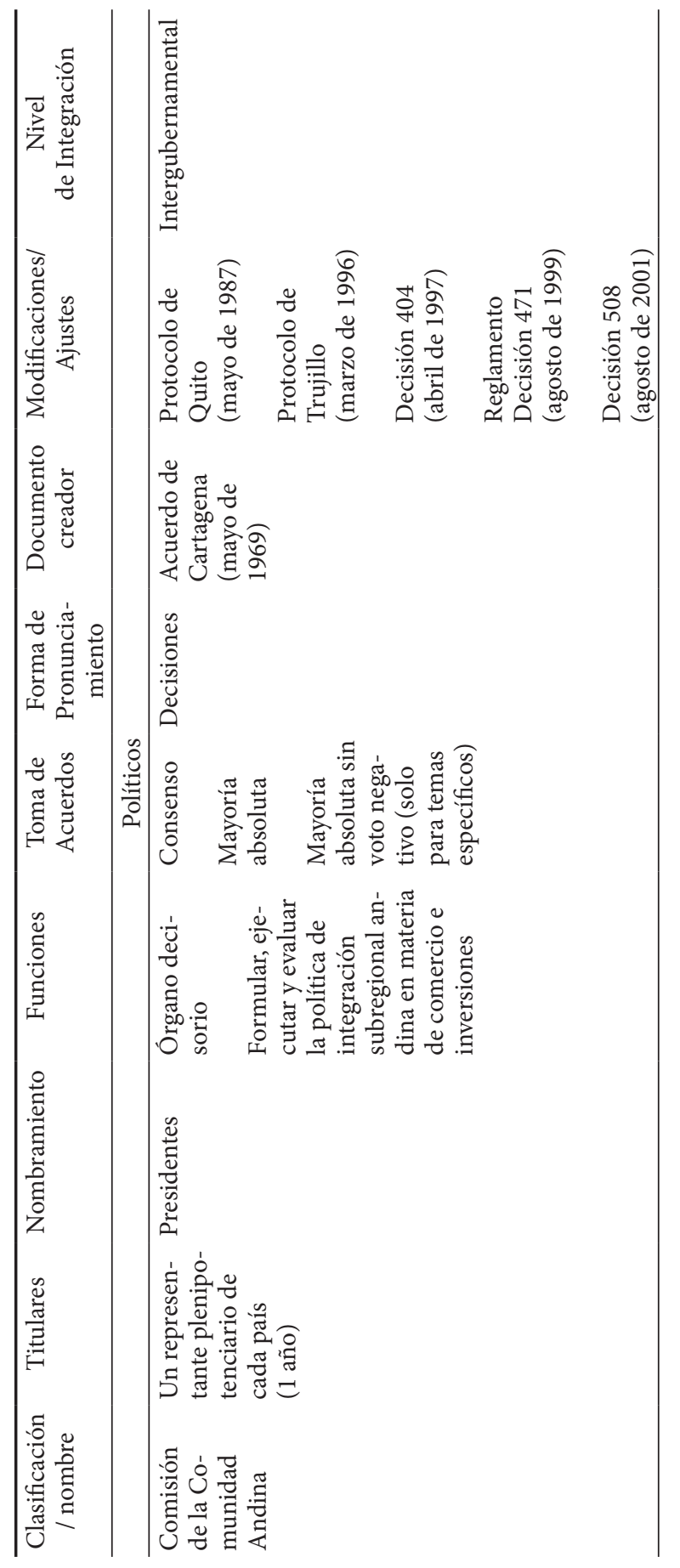

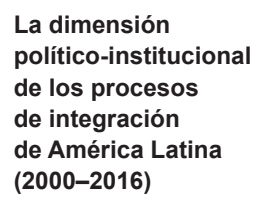

Alberto Rocha Valencia
Cuadro 10.

continuado 


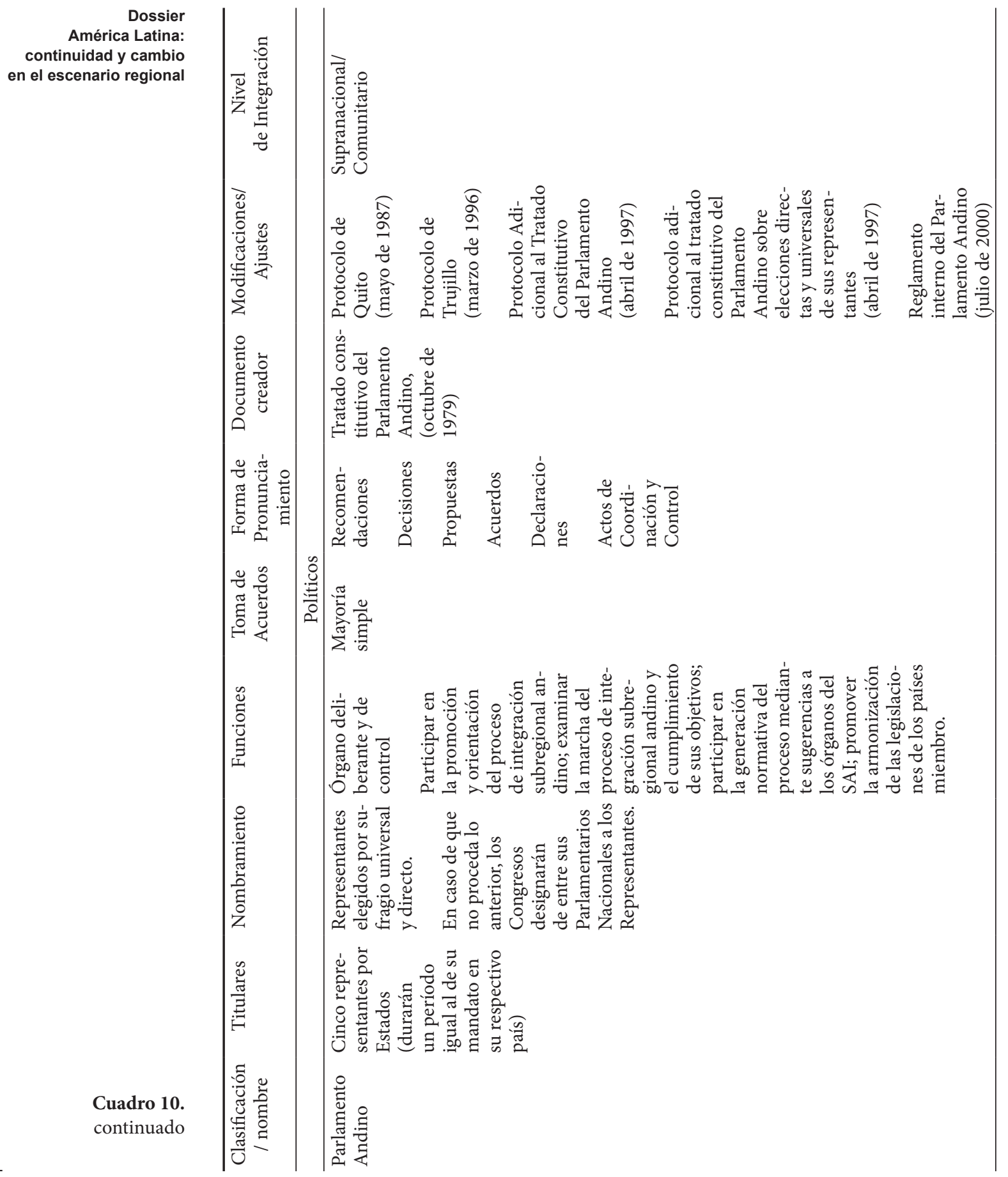




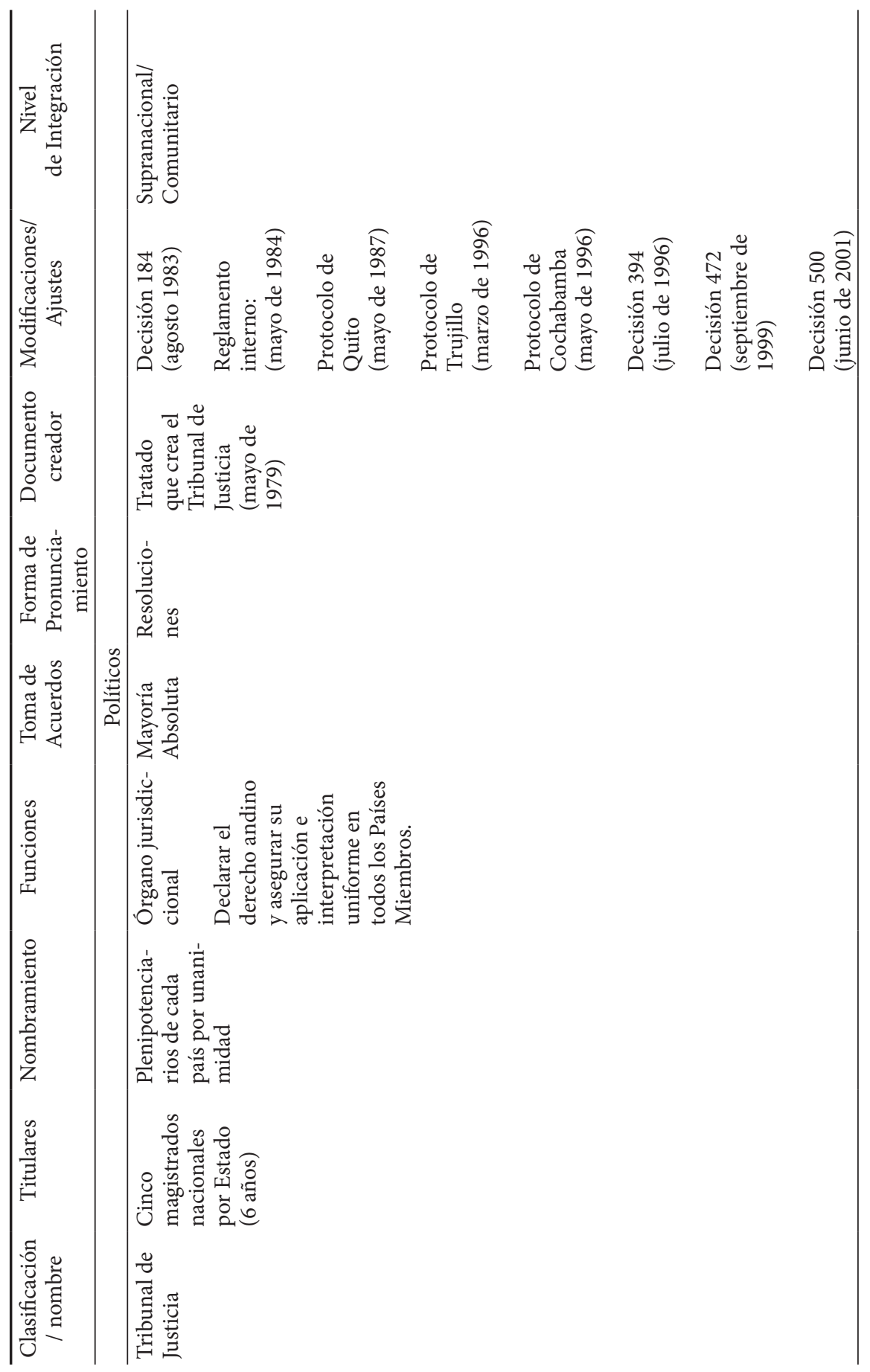

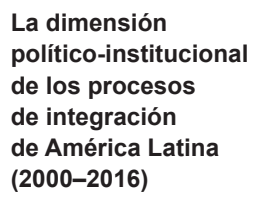

Alberto Rocha Valencia
Cuadro 10.

continuado 


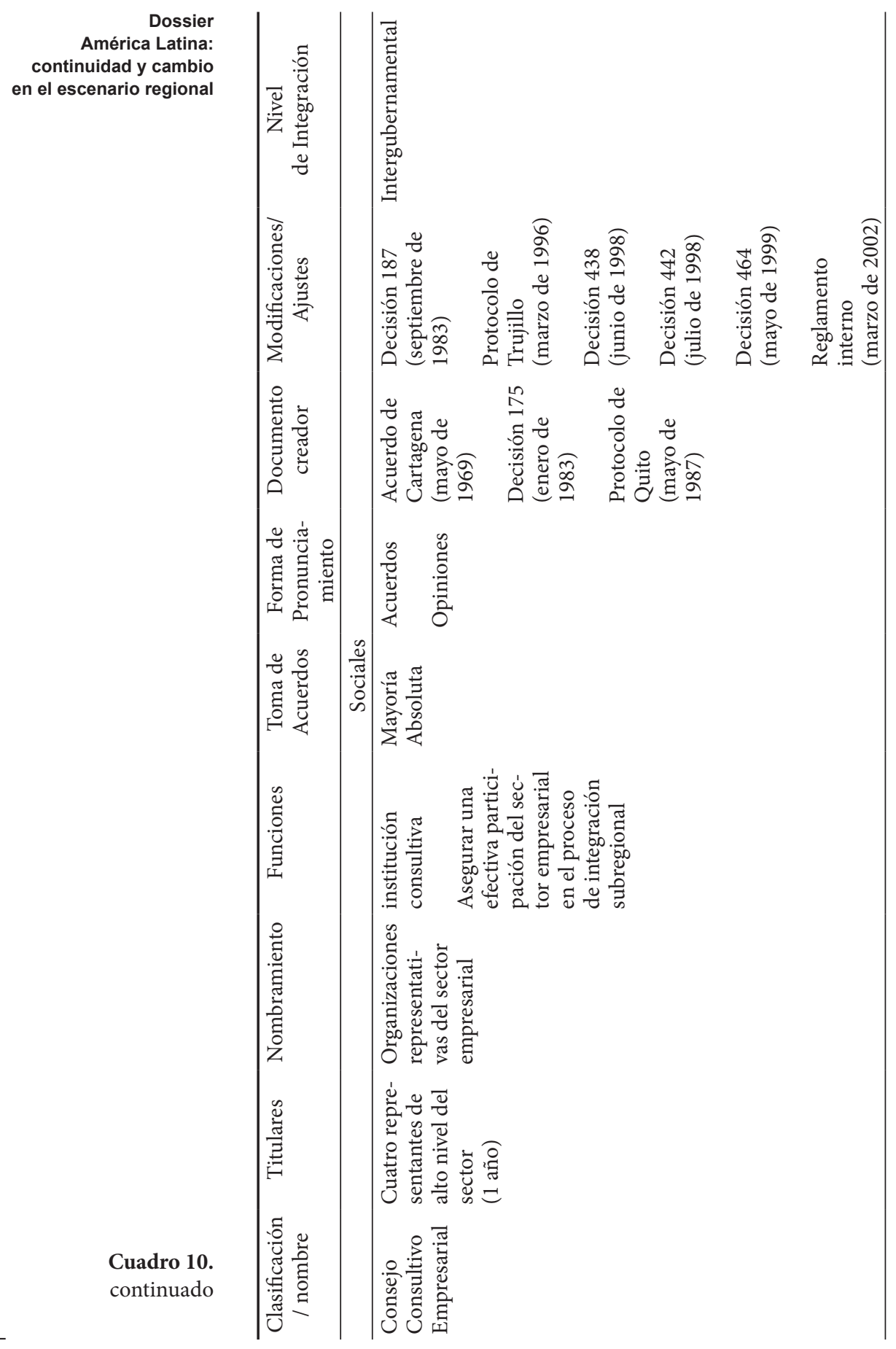




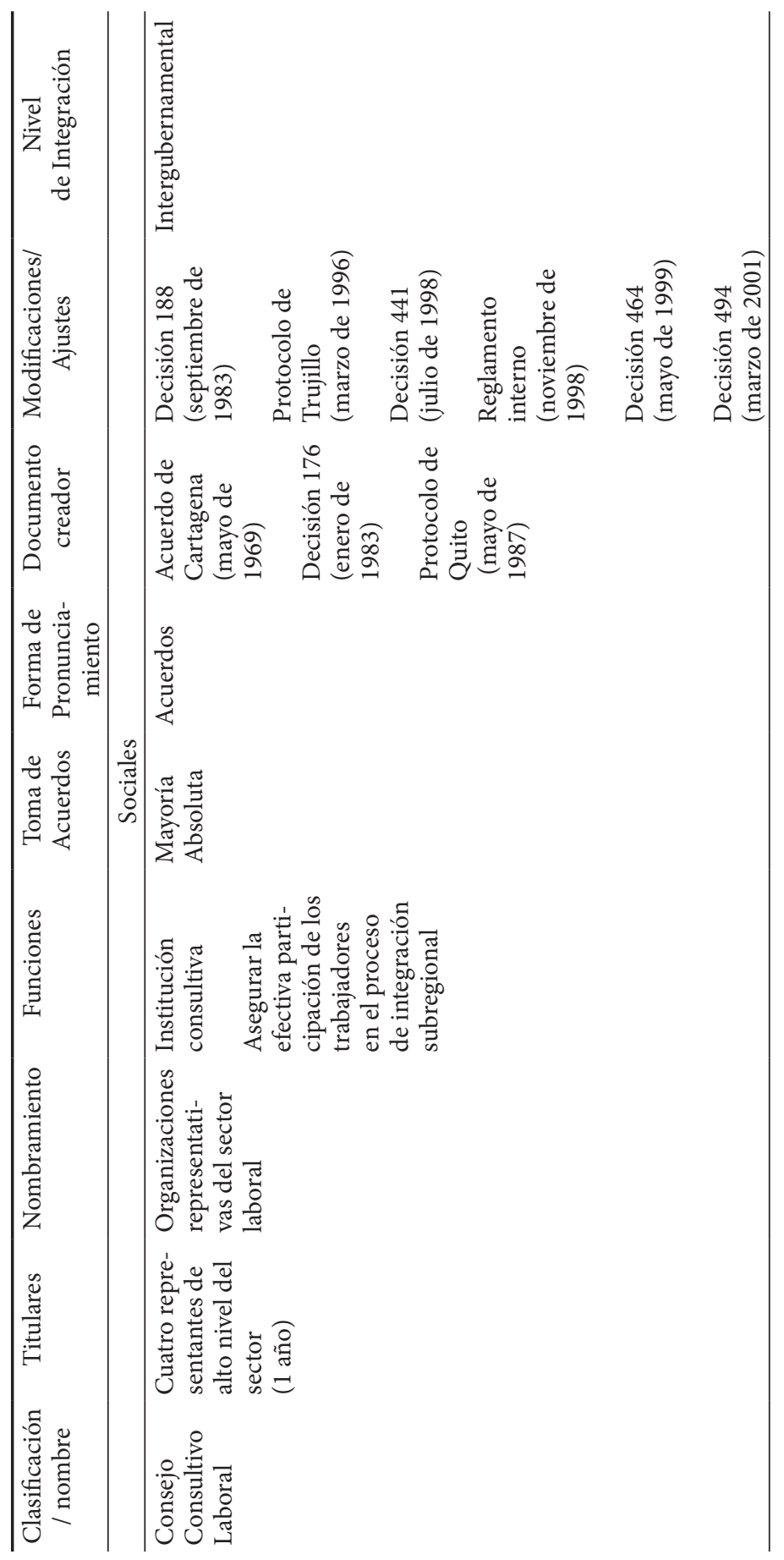

La dimensión político-institucional de los procesos de integración de América Latina (2000-2016)

Alberto Rocha Valencia

Cuadro 10.

continuado 


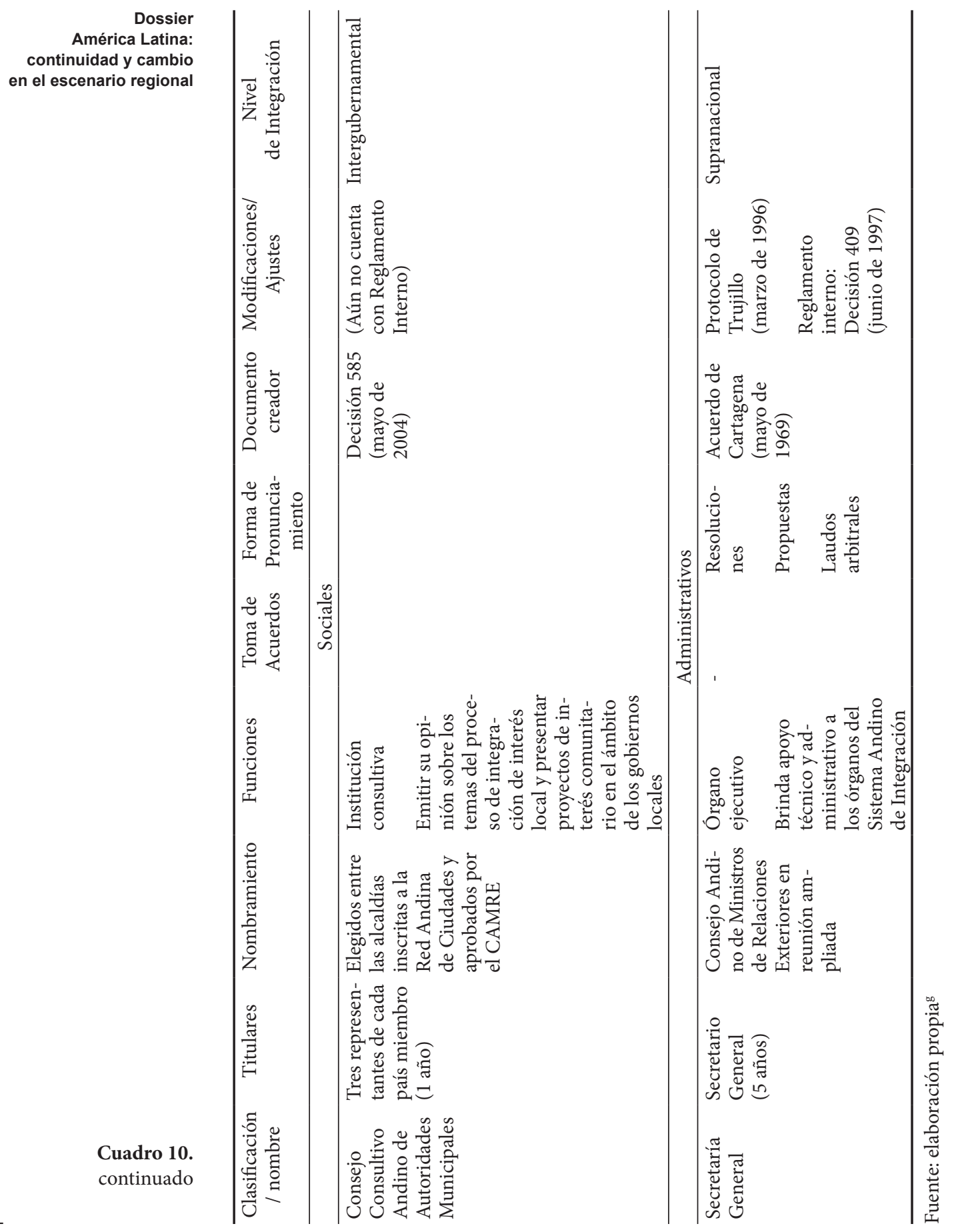




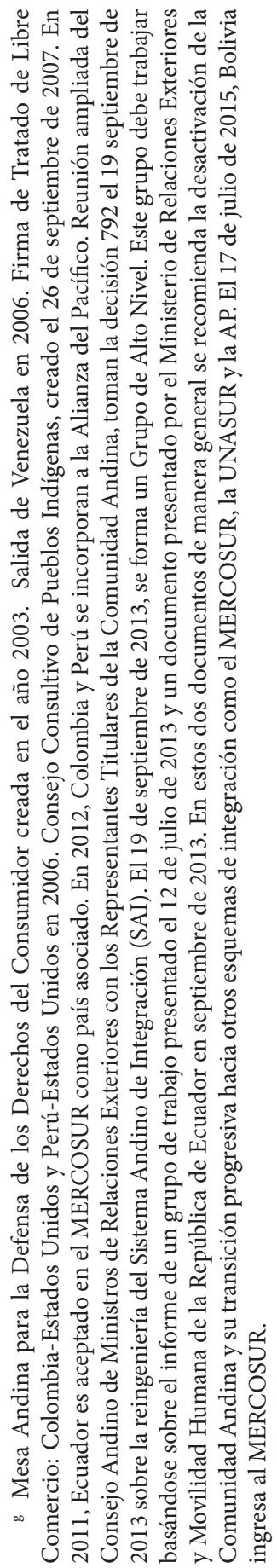

La dimensión político-institucional de los procesos de integración de América Latina (2000-2016)

Alberto Rocha Valencia 


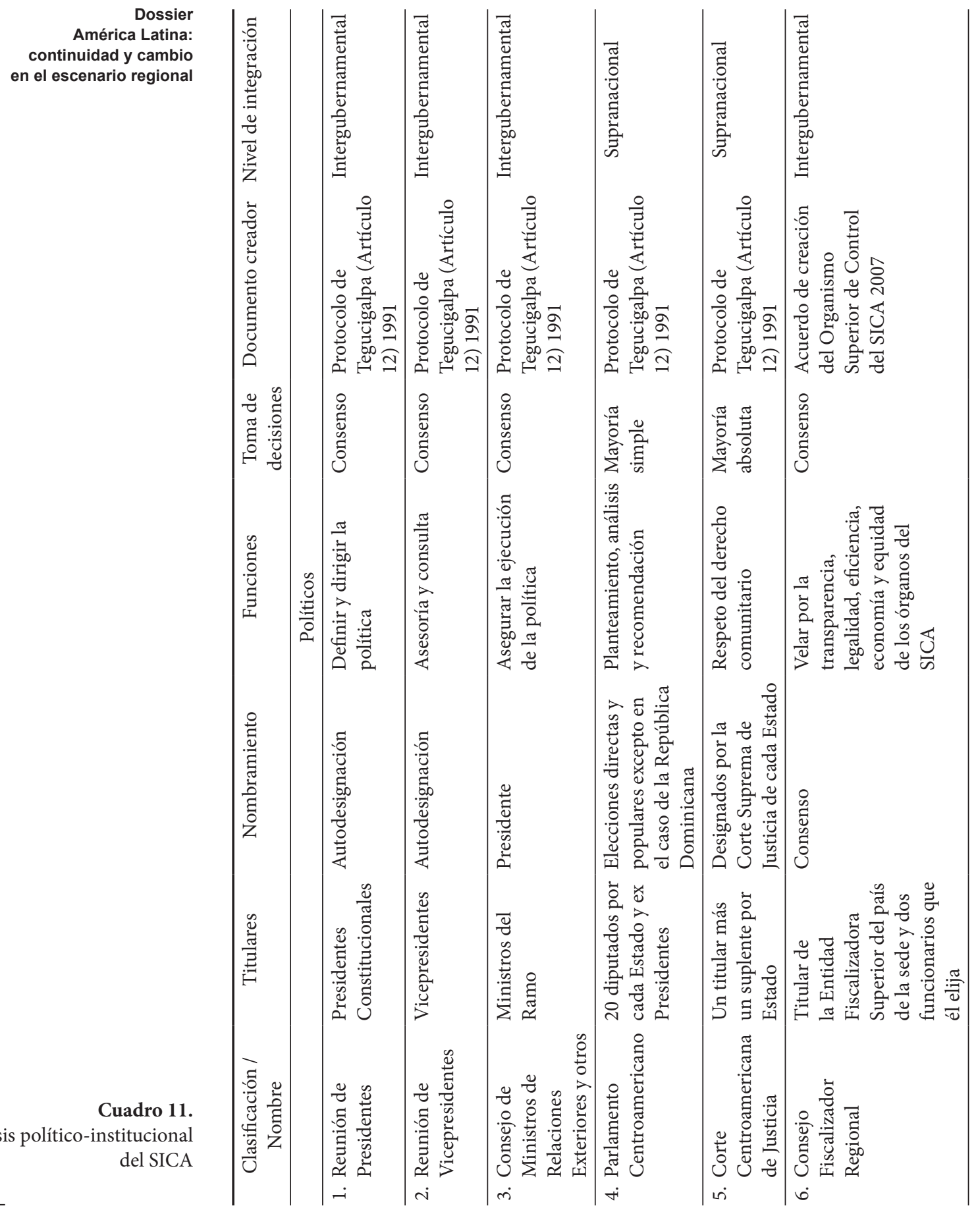




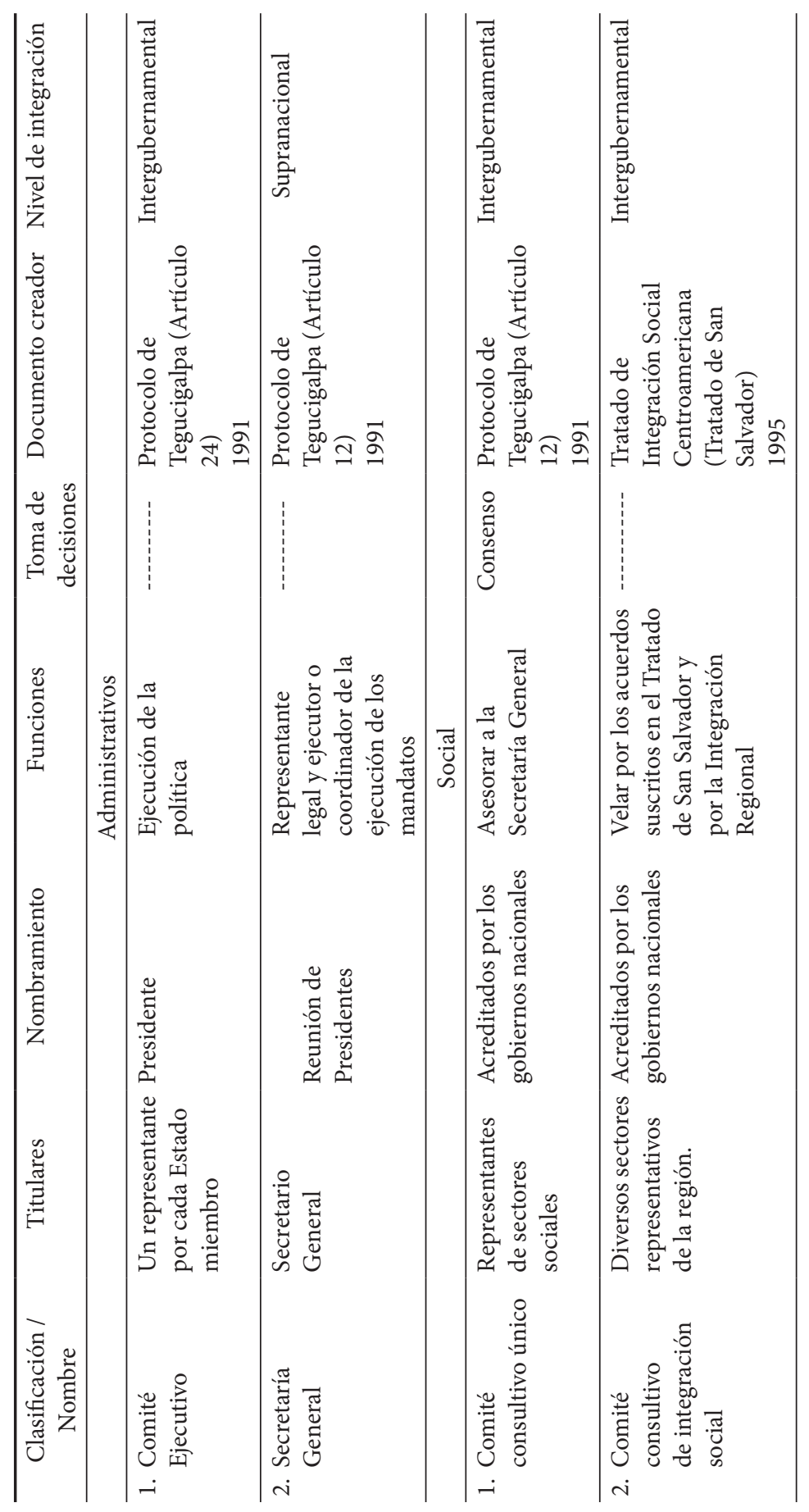

La dimensión político-institucional de los procesos de integración de América Latina (2000-2016)

Alberto Rocha Valencia

Cuadro 11. continuado 


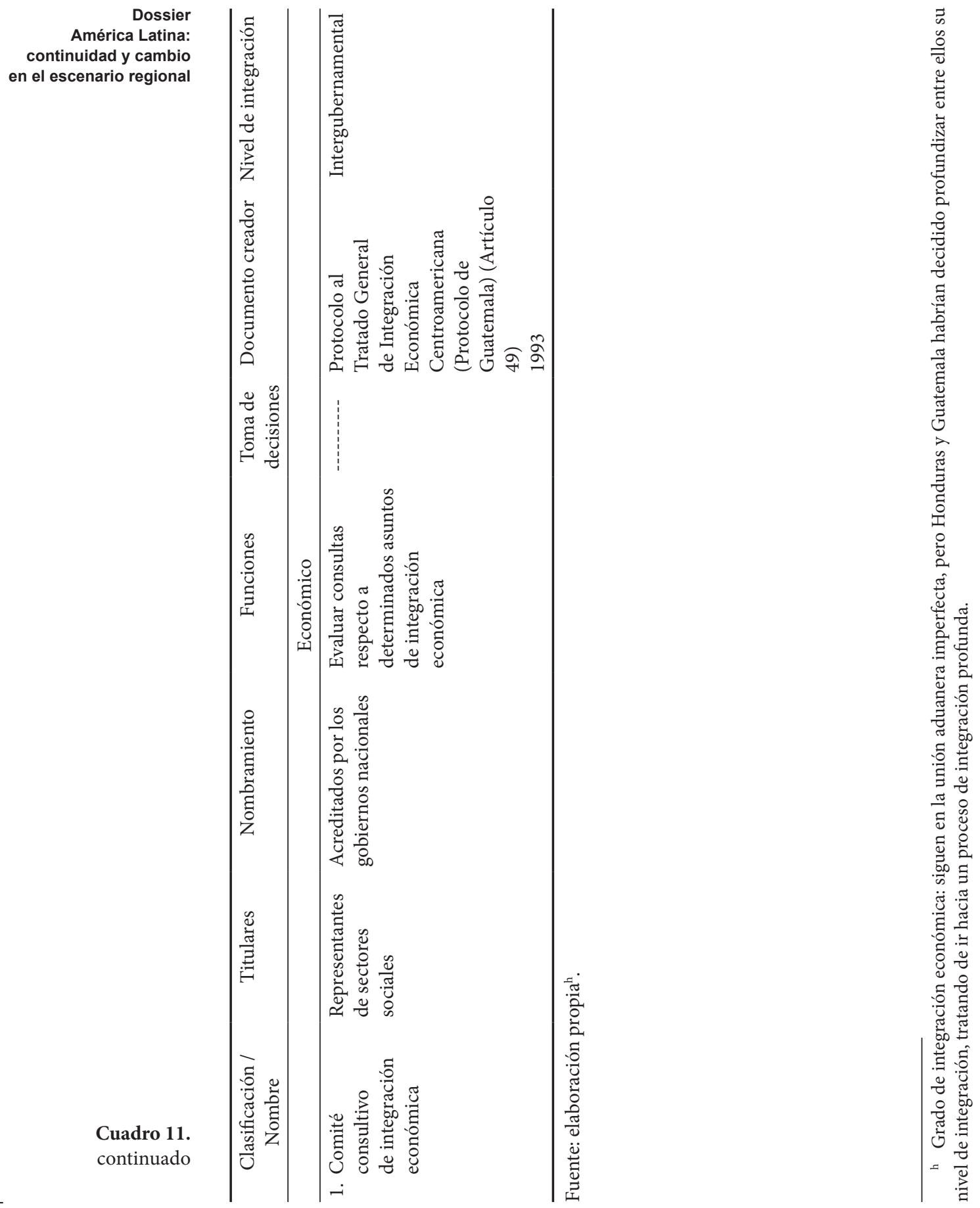




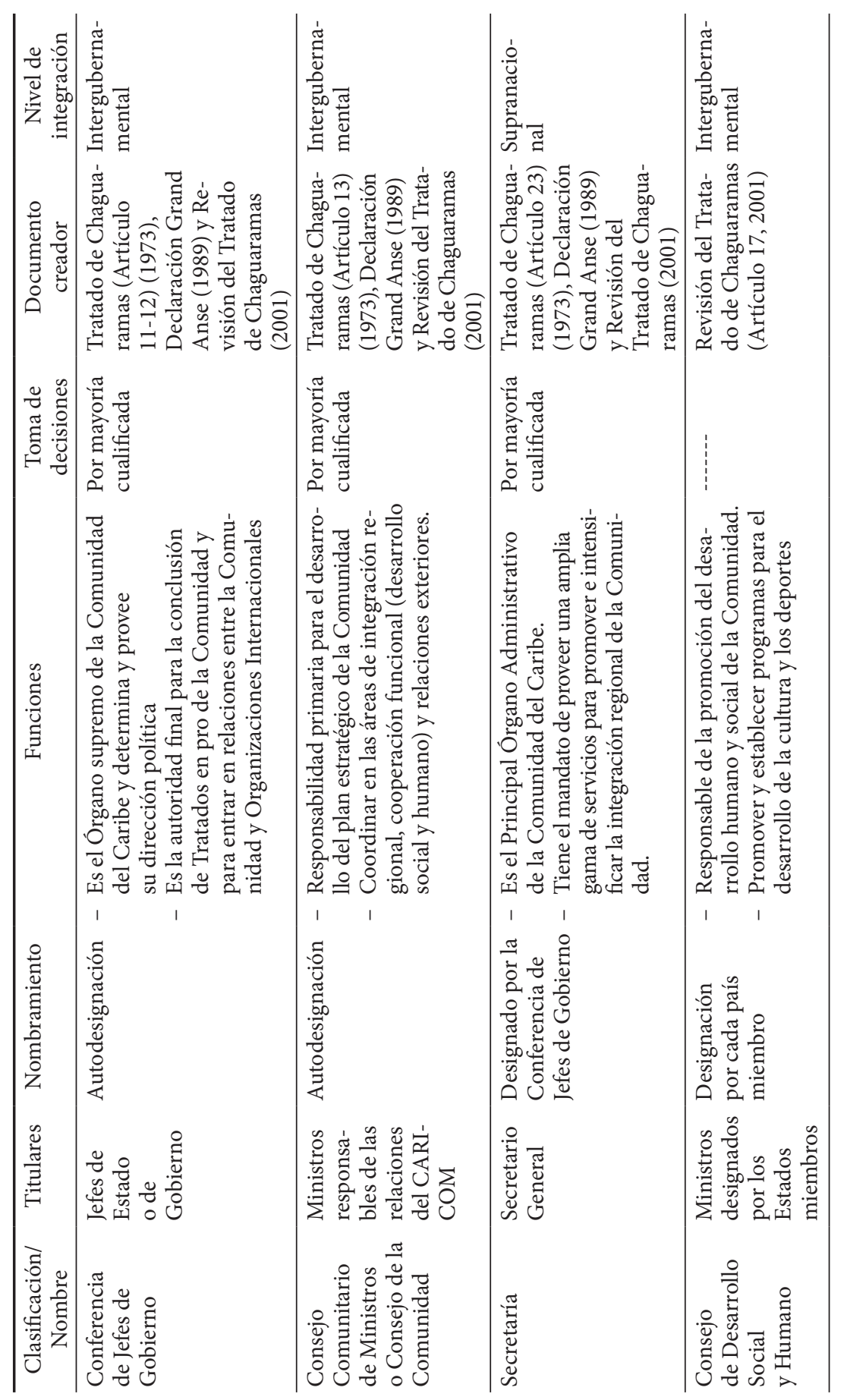

La dimensión
político-institucional
de los procesos
de integración
de América Latina
(2000-2016)
Alberto Rocha Valencia

Cuadro 12.

Análisis político-institucional de la CARICOM 


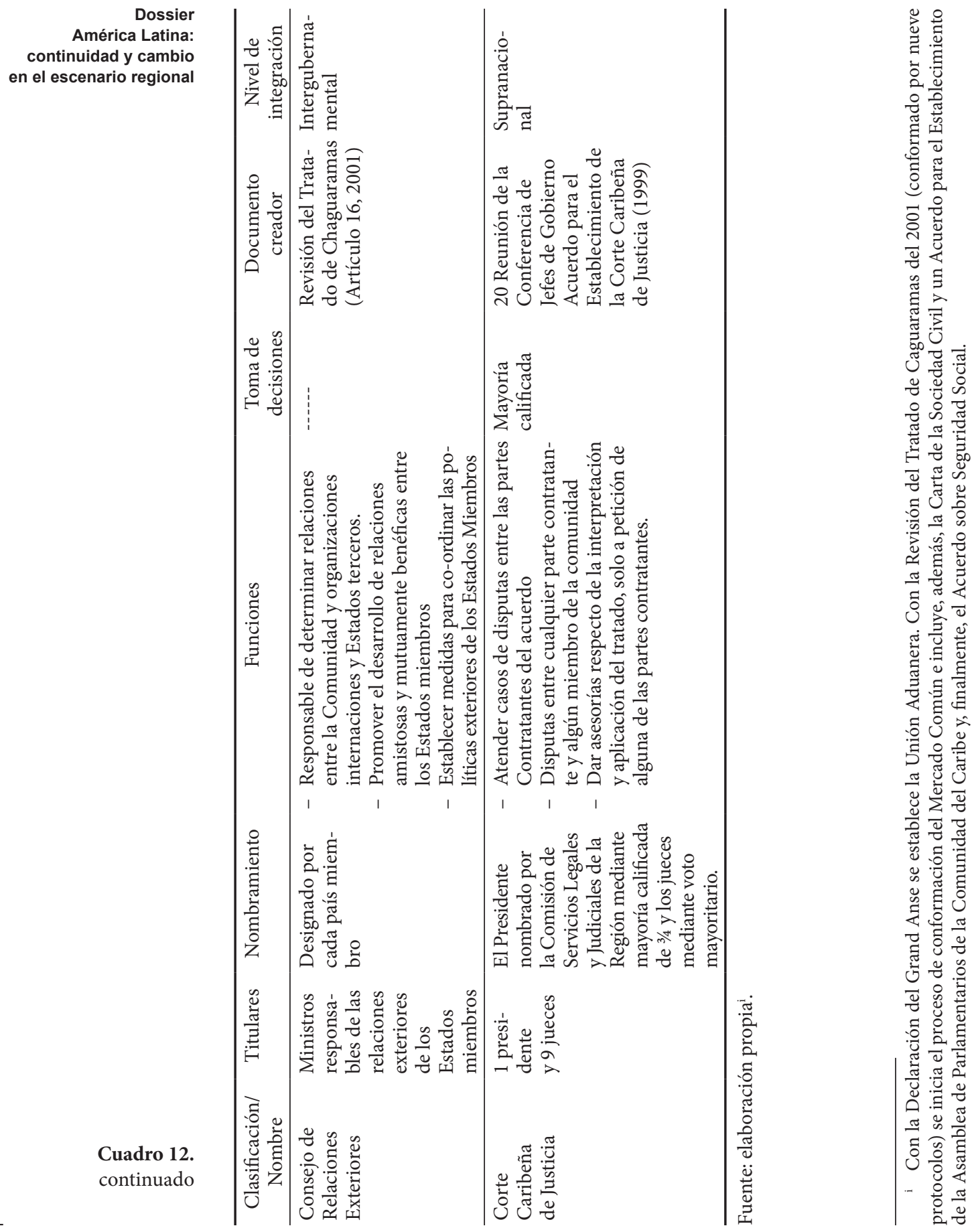



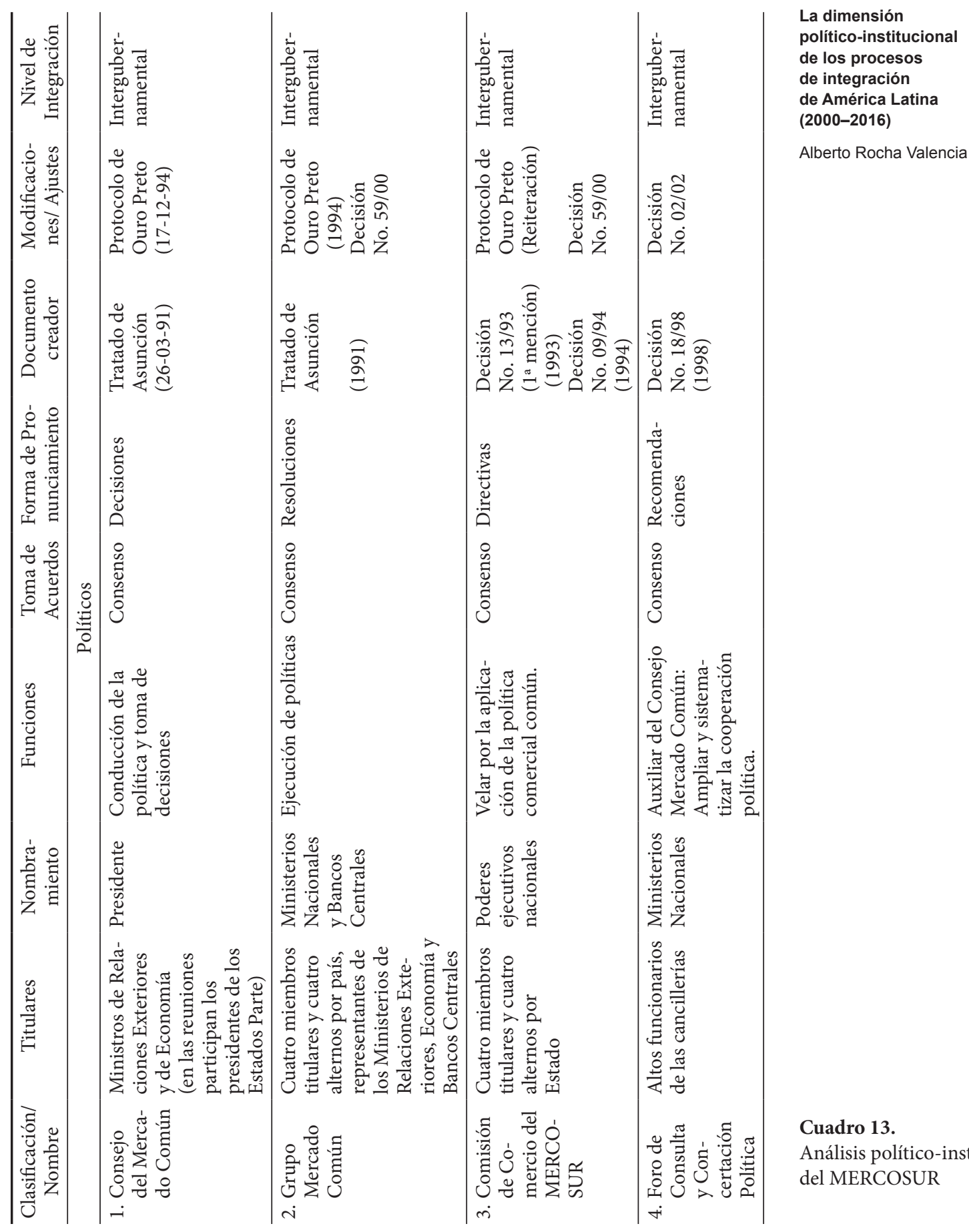

Alberto Rocha Valencia




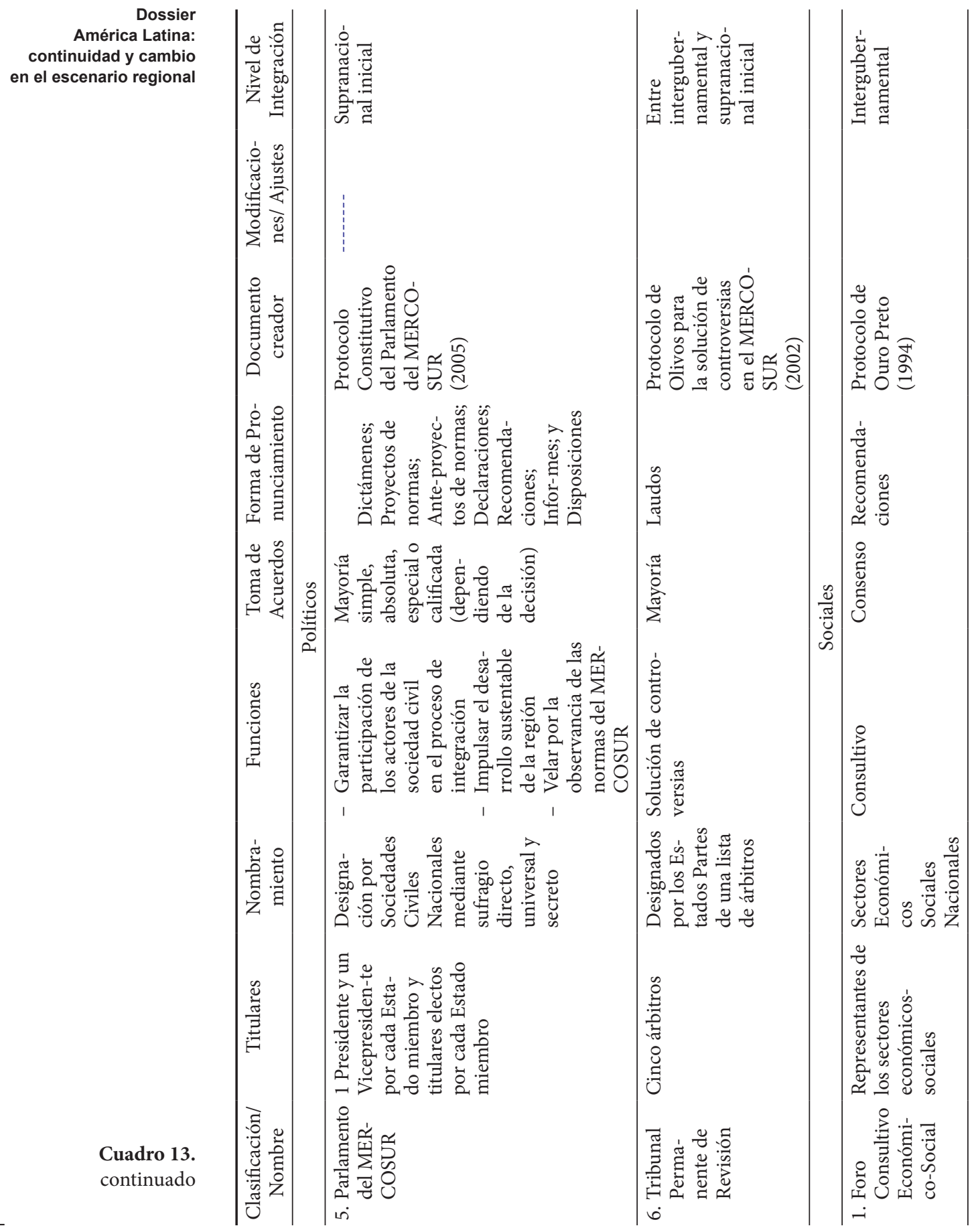




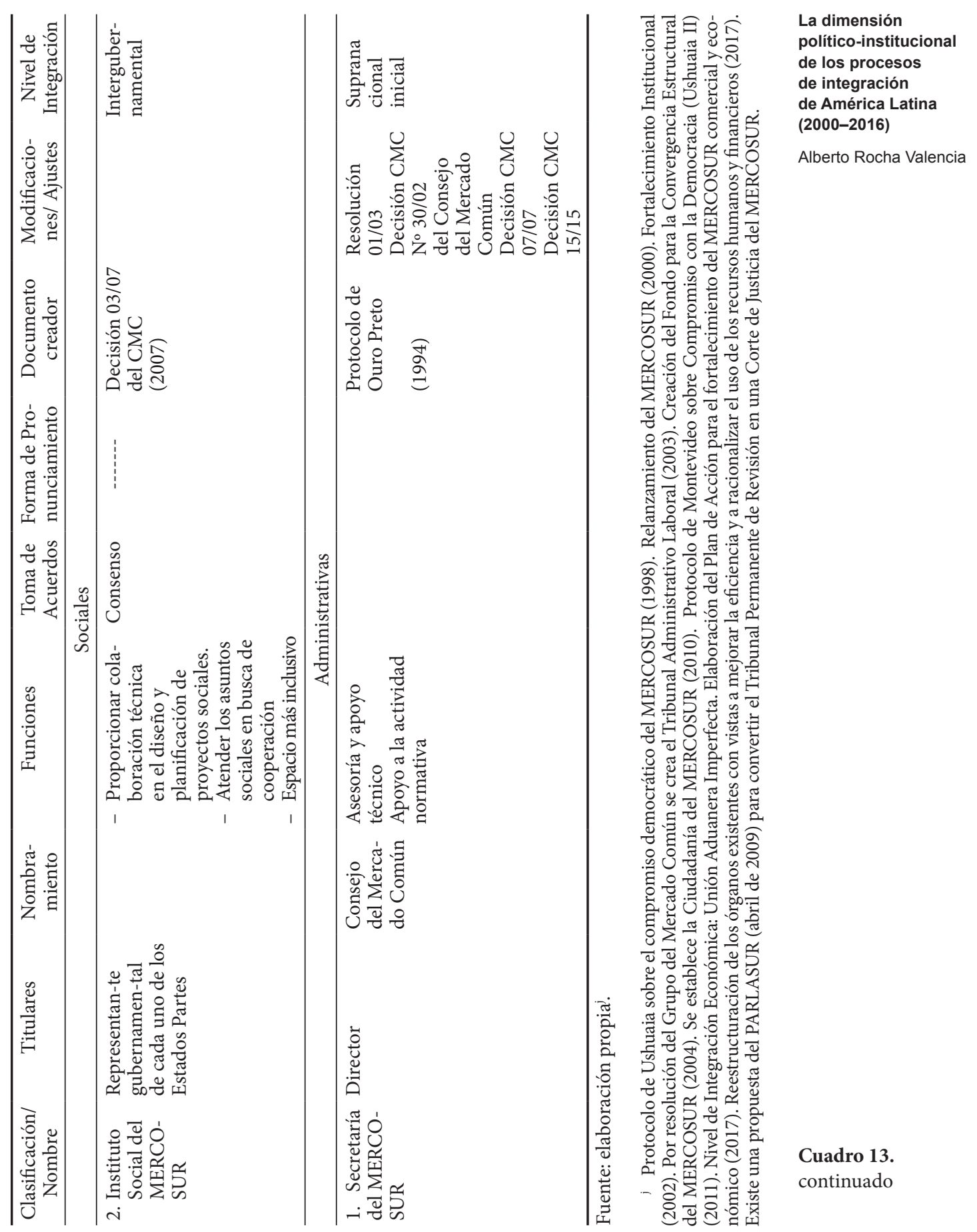


América Latina:

continuidad y cambio en el escenario regional

\section{La CELAC y la gobernabilidad regional}

Podemos decir que la gobernabilidad de nuestra región fue un asunto continental, esto por lo menos hasta antes de la existencia de la CELAC. El Grupo de Río, por sus limitaciones, fue el primer ensayo tímido y limitado que nos recordó siempre lo que nos hacía falta en la región: una gobernabilidad adecuada. La gobernabilidad continental siempre fue un asunto heterónomo, es decir, un arreglo político-institucional del hegemón mundial y continental norteamericano para mantener bajo control geopolítico la región: OEA, TIAR y otros mecanismos a los cuales se sumó después la Cumbre de las Américas.

La CELAC es el segundo ensayo osado (práctica) y extenso (diseño) y de una gobernabilidad regional autónoma:

- Un foro político y diplomático regional (incluyente de todos los 33 países). Una cumbre de jefas y jefes de Estado y Gobierno de la región, con capacidad de dotar de dirección política a la región, mismo si tenía que hacerlo por consenso.

- Una reunión de ministros y ministras de la región, así como de un Cuarteto (con su presidencia Pro-Témpore), capaces de impulsar una suerte de gobernanza regional y generar una dinámica interna regional multisectorial.

- Un Cuarteto (con su presidencia Pro-Témpore), habilitado para relacionar a la región con países y regiones del mundo.

La CELAC es un ensayo histórico y un experimento trascendental para la región. Nunca antes en la región se había logrado plasmar un nivel importante de autonomía (capacidades regionales, toma de decisiones adecuadas y perspectiva histórica propia), pues la región comenzó a ser gobernada en función de sus propias perspectivas de desenvolvimiento histórico (Rocha Valencia 2014: 27-44, 2018: 41-60).

La CELAC no estuvo sola en este primer despliegue gubernamental regional:

- Recibió apoyos de la UNASUR y el Foro de Tuxtla Gutiérrez, dos foros políticos mesoregionales.

- Recibió sustento del MERCOSUR, la CAN, el SICA, la CARICOM, la AEC, la ALBA y la AP.

- También fue apoyada hasta 2015 por todos los gobiernos progresistas y neoliberales.

Con la CELAC se configuró el primer bosquejo de gobernabilidad-gobernanza regional, a partir del cual se había proyectado continuar trabajando por una mejor vinculación internacional y un diferente posicionamiento mundial de nuestra región. 


\section{Conclusiones}

En el tercer periodo del proceso de integración regional, consideramos que el logro mayor es haber logrado la configuración de un bosquejo de gobernabilidad-gobernanza autónoma regional. Por gobernabilidad autónoma regional entendemos un ensayo de dirección política propia y de una gobernanza adecuada para impulsar una dinámica interna-externa con la finalidad de buscar el fortalecimiento de las capacidades internas (materiales, semimateriales e inmateriales) y el despliegue de la región en el mundo.

Este bosquejo de gobernabilidad-gobernanza regional fue apuntalado por la CELAC y se sustentó en el conjunto heterogéneo de procesos mesoregionales, subregionales y bilaterales. Lo importante fue que este diseño primero de gobernabilidad-gobernanza permitió generar una dinámica interna regional de coordinación y convergencia de todos los procesos de integración existentes y una dinámica externa regional de relacionamiento internacional sur-sur y norte-sur. Nunca antes la región se había unificado y cohesionado tanto como en el tercer periodo de su integración regional.

En el cuarto periodo del proceso de integración regional nos encontramos en una total incertidumbre. La CELAC se encuentra casi paralizada como foro político-diplomático, no hay consenso y tampoco cumbres presidenciales. La UNASUR también se encuentra casi detenida como foro político-diplomático, tampoco hay consenso y un grupo de países se ha retirado temporalmente. Todo indica que este proceso será reestructurado (de hecho, ya fue reestructurado como Foro PROSUR). El MERCOSUR está en proceso de reorientación política y posiblemente también será reestructurado. La multidimensionalidad y la institucionalidad que le corresponde causa temor en los nuevos gobiernos conservadores y neoliberales. La CAN posiblemente desaparecerá, como la primera víctima del bilateralismo exacerbado. Todo bilitateralismo extremo, dicho sea de paso, termina tarde o temprano por cuestionar la cohesión del proceso de integración regional o subregional. El SICA y la CARICOM muestran un bajo perfil y a la espera de los acontecimientos. La AP es el único proceso que se mantiene y persiste porque está apuntalado por los gobiernos conservadores neoliberales en plaza que buscan redefinir y reorientar el llamado "regionalismo abierto".

Lo cierto es que en el mundo actual en crisis el experimento unipolar estadounidense y se avanza rápidamente hacia un escenario de multipolaridad sumamente competitiva y conflictiva. En ese contexto, las tres regiones más importantes del mundo (América del Norte, Europa y Asia Pacífico) tratan de reconstituirse, fortalecerse y reimpulsarse de acuerdo con esta nueva situación mundial. La pregunta que queda planteada es sobre la estrategia que seguirá América Latina para proseguir con su proceso de integración regional en los nuevos tiempos de la multipolaridad mundial. La única respuesta que tenemos es el proceso de convergencia Alianza del Pacífico -
La dimensión

político-institucional

de los procesos

de integración

de América Latina

(2000-2016)

Alberto Rocha Valencia 
Dossier América Latina: continuidad y cambio en el escenario regional
MERCOSUR. cuyos avances son los siguientes: Reunión Informativa del MERCOSUR y la Alianza del Pacífico, Colombia (01/11/2014); Primera Reunión de Cancilleres AP-MERCOSUR, Chile (24/11/2014); Propuesta de Plan de Acción remitida a la AP (2015); Reunión de los presidentes Mauricio Macri y Michelle Bachelet (12/2016); Reunión de Ministros del MERCOSUR y la AP para crear hoja de ruta para acercamiento (07/04/2017); Realización del Seminario MERCOSUR-Alianza del Pacífico, Mendoza (19/07/2017); y, Primera reunión del Grupo de Alto Nivel y Grupo del Mercado Común (04/08/2017).

\section{Referencias bibliográficas}

ALBA-TCP Página Oficial (2010), Bolivarian Alliance for the Peoples of Our America - Peoples' Trade Treaty (ALBA-TCP), recuperado de http://alba-tcp.org (documento deshabilitado).

Bizzozero L. Y., Vaillant M. (eds.) (1996), La inserción internacional del MERCOSUR ¿Mirando al Sur o mirando al Norte?, Arca, Montevideo.

Briceño J. (2018), Las teorías de la integración regional: más allá del eurocentrismo, Universidad Cooperativa de Colombia, Bogotá.

Caetano G. Y., Perina R. (eds.) (2000), Parlamentos e instituciones en el Mercosur: los nuevos desafíos, Editorial Lima, Montevideo.

Cairo H. Y., De Sierra G. (comp.) (2008), América Latina, una y diversa: teorías y métodos para su análisis, Editorial Alma Mater, San José.

Camou A. (2008), Gobernabilidad y democracia, IFE, Ciudad de México.

De Sierra G. (comp.) (2001), Los rostros del MERCOSUR. El difícil camino de lo comercial a lo societal, CLACSO, Buenos Aires.

De Sierra G., Bernales M. (comps.) (2004), Democracia, gobernanza y desarrollo en el Mercosur. Hacia un proyecto propio en el siglo XXI, UNESCO-CLACSO, Montevideo.

Dror Y. (1994), La capacidad de gobernar: informe al Club de Roma, Galaxia Gutenberg.

Garzón J. (2015), Latin American Regionalism in a Multipolar World, Instituto de la Universidad de Europa, Roma.

Garzón J., Nolte D. (2018), The New Minilateralism in Regional Economic Governance: Cross-regionalism and the Pacific Alliance, en: Handbook of South American Governance, P. Riggiorozzi, C. Wylde (eds.), Routledge, London/New York.

Gudynas E. (2006), Los fantasmas de la integración regional, "Revista del Sur", no 166, julioagosto 2006.

Lander E. (2004), ¿Modelos alternativos de integración? Proyectos neoliberales y resistencias populares, CLACSO, Buenos Aires.

Mellado N. (ed.) (2009), Mercosur y Unasur, ¿hacia dónde van?, Editorial Lerner, Córdoba.

Mellado N. (ed.) (2010), Gobernabilidad e instituciones en la integración regional, Editorial Lerner, Córdoba.

Mellado N. (ed. y dir.) (2012), Instituciones, comercio y cooperación monetaria en la integración sudamericana: sus efectos sobre la gobernabilidad regional, Editorial Lerner, Córdoba. 
Prats J. (2000), Previniendo crisis de gobernabilidad democrática. Un aspecto olvidado de la cooperación política, "Revista Electrónica DHIAL", no 3, disponible en: http://www.iigov.org/dhial/

Prats J. (2001), Gobernabilidad democrática para el desarrollo humano: marco conceptual y analítico, "Instituciones y Desarrollo", vol. 10.

Prats J. (2003), El concepto y el análisis de la gobernabilidad, disponible en: http://www. researchgate.net/scientific-contributions/21913076_Joan_Oriol_Prats

Preciado Coronado J. et al. (2013), La comunidad de Estados Latinoamericanos y Caribeños. Integración postneoliberal, neoliberal ortodoxa y contrahegemónica, CLACSO - ARCIS, Santiago de Chile.

Preciado Coronado J. (coord.) (2018), Dimensiones, estrategias y alternativas de la integración autónoma para América Latina y el Caribe. Desafíos para el caso mexicano (2010-2015), tomo I, Historia, economía y políticas exteriores, Universidad de Guadalajara.

Preciado Coronado J. (coord.) (2018), Dimensiones, estrategias y alternativas de la integración autónoma para América Latina y el Caribe. Desafíos para el caso mexicano (2010-2015), tomo II, Política, geopolítica y ecología política, Universidad de Guadalajara.

Preciado Coronado J. (coord.) (2018), Dimensiones, estrategias y alternativas de la integración autónoma para América Latina y el Caribe. Desafíos para el caso mexicano (2010-2015), tomo III, Cultura, educación, ciencia, tecnología y cibercrítica, Universidad de Guadalajara.

Preciado Coronado J. (coord.) (2018), Dimensiones, estrategias y alternativas de la integración autónoma para América Latina y el Caribe. Desafíos para el caso mexicano (2010-2015), tomo IV, Dimensión social, turismo y crimen organizado: conclusiones generales, desafíos de la integración autónoma para el caso mexicano, Universidad de Guadalajara.

Preciado Coronado J., Rocha Valencia A., Estay J. (eds.) (2006), El MERCOSUR en la integración latinoamericana y caribeña. Contextos, dimensiones y procesos, UdeG-BUAP, Guadalajara.

Regueiro L. (2008), Los TLC en la perspectiva de la acumulación estadounidense. Visiones desde el Mercosur y el ALBA, CLACSO, Buenos Aires.

Rocha Valencia A. (2001), La dimensión política de los procesos de integración regional y subregional de América Latina y el Caribe, en: La integración política latinoamericana y caribeña: un proyecto comunitario para el siglo XXI, J. Preciado Coronado (coord.), AUNA, UdeG, Rectoría de Historia de la UMSNH, Morelia.

Rocha Valencia A. (2003), Configuración politica de un mundo nuevo. Las dimensiones políticas de lo global, lo supra regional, lo posnacional y lo local, Universidad de Guadalajara, Guadalajara.

Rocha Valencia A. (2007), La integración regional de ALC ante el TLCAN y el ALCA: el triángulo asimétrico de la hegemonía y las subhegemonías en las Américas, en: Globalización y bloques económicos: mitos y realidades, J.L. Calva (coord.), UNAM, Porrúa, México D.F..

Rocha Valencia A. (2014), El proceso político-diplomático hacia la constitución de la Comunidad de Estados Latinoamericanos y Caribeños: integración, autonomía y unidad, en: Integración, seguridad y democracia en América Latina, I. Medina Núñez y C. Oliva Campos (coord.), ITESO, Guadalajara.

Rocha Valencia A. (2018), La CELAC en el proceso de construcción de una región autónoma global, en: Dimensiones, estrategias y alternativas de la integración autónoma para América Latina y el Caribe. Desafíos para el caso mexicano (2010-2015). Tomo II, Política, Geopolítica y Ecología Política, J. Preciado Coronado (coord.), UdeG, Guadalajara.

Rocha Valencia A., Preciado Coronado J. (comp.) (1997), América Latina realidad, virtualidad y utopía de la integración, UdeG, Guadalajara.

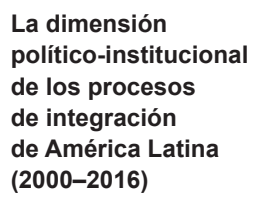

Alberto Rocha Valencia 
Dossier América Latina: continuidad y cambio en el escenario regional
Rocha Valencia A., Preciado Coronado J., Marum Espinosa, E. (coords.) (2002), Dinámicas y escenarios estratégicos de la integración en América Latina, UdeG, Guadalajara.

Rocha Valencia A. et al. (2003), La integración regional de América Latina en una encrucijada histórica, UdeG, Guadalajara.

Rocha Valencia A., Preciado Coronado J., Cairo Carou H. (eds.) (2007), La construcción de una región. México y la geopolítica del plan Puebla-Panamá, Catarata, Universidad Complutense de Madrid.

Rocha Valencia A., Preciado Coronado J. (coords.) (2008), Proyectos y estrategias de integración. América Latina y el Caribe en el contexto de América del Norte y Europa, UdeG, Guadalajara.

Rocha Valencia A., Morales Ruvalcaba D. (2013), Desafíos en la construcción de la Unión de Naciones de Suramérica, en: Mercosul a Unasul: Avanços do Processo de Integração, R. M. Gadelha (org.), Educ-Fapesp, São Paulo.

Rocha Valencia A., Loza M., Lahuerta M., Nogueira M. (coord.) (2014), Brasil y México en América Latina del siglo XXI, UdeG, Guadalajara.

Rocha Valencia A., Morales Ruvalcaba D. (2015), Geopolítica de la Alianza del Pacífico en América Latina, el continente americano y Asia Pacífico, en: Perspectivas y oportunidades de la Alianza del Pacífico, I. Rodríguez Aranda y E. Vieira Posada (ed.), CESA, Bogotá.

Rocha Valencia A., Preciado Coronado J. (coords.) (2016), El proceso de integración de América Latina en el siglo XXI. La competencia-cooperación entre México y Brasil con la presencia de Estados Unidos y China, UdeG, Guadalajara, México.

Rosenthal G. (1993), La integración regional en los años noventa, "Revista de la CEPAL", no 50, Santiago de Chile.

Salazar J. (1993), El resurgimiento de la integración y el legado de Prebisch, "Revista de la CEPAL", no 50, Santiago de Chile.

Sanahuja J. (2006), Regionalismo e integración en América Latina: balance y perspectivas, disponible en: https://www.researchgate.net/publication/28248897_Regionalismo_e_ integracion_en_America_Latina_Balance_y_perspectivas

Sanahuja J. (2009), Del "regionalismo posliberal". Crisis y cambio en la integración regional en América Latina y el Caribe, "Anuario de la Integración Regional de América Latina y el Gran Caribe", no 7, Buenos Aires.

SELA (2004), La integración y sus instituciones en América Latina y el Caribe, SELA, no 10, Caracas.

SELA (2018), Una visión perspectiva de la integración latinoamericana y caribeña, SELA, no 2, marzo, Caracas.

Vieira E. (2006), Développements régionaux d'espaces sous-nationaux, transfrontaliers et transnationaux: une option pour l'intégration de l'Amérique Latine, Pontificia Universidad Javeriana, Bogotá. 